\title{
THE APPLICATION OF TIME-LAPSE PHOTOGRAPHY IN WORK SIMPLIFICATION STUDIES OF CONSTRUCTION OPERATIONS
}

JUNE 1969 - NUMBER 17

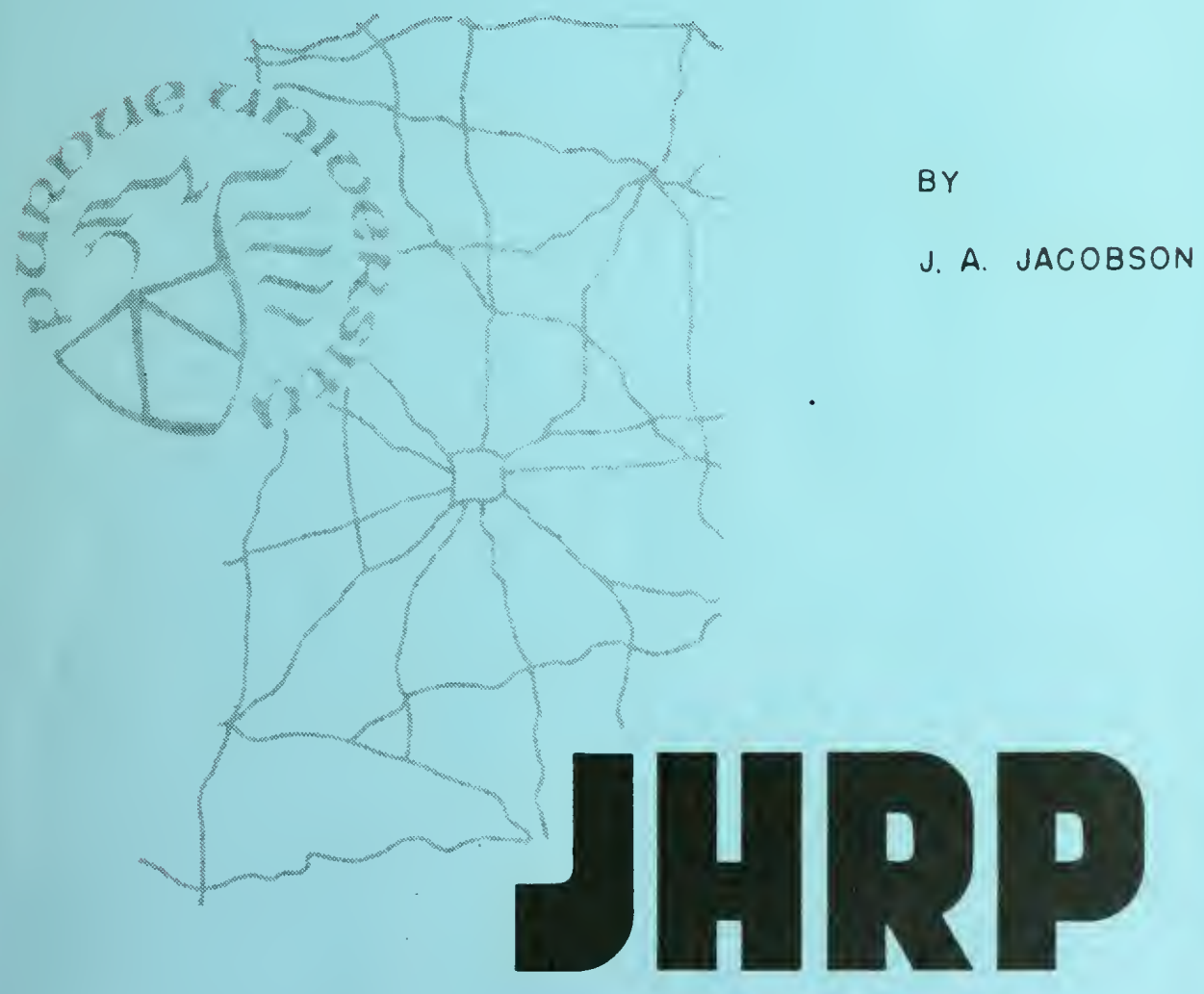

JOINT HIGHWAY RESEARCH PROJECT PURDUE UNIVERSITY AND 

THE APPLICATIOI OF TIAE-LAPSE RHOTOEREPYY IV WORK STMPLIFICATIOH STUDIES OR CORSTRUCTION OPERATIONS

TO: J. F。 Mclaughiln, Director

Joint Hightoy Research Project

Faos: H. L。 Michael, Associate Director

Joint Righay Research Project

June 17,1969

File: $9-11-4$

Project: $\quad C-36-67 D$

The attached Final Eeport "The Application of IItra-Lapse Photography in Work Simplification Studies of Construction Operations" hes been authored by Mr. Jimy A. Jacobson, Graduate Assistant in Research on our staff. Mr. Jacobson also ucilized the zesearch for his MSCD degre? thesis requirement. Professor John A. Havers directed the research and serjed as nrincipal sdvisor.

The research study was approved about two years ago to study the application of time-lapse photography in work eimplification studies of construction operations. The operation of bridge deck construction was studied and some inefficlencies which warranced forml work simplificetion studies were noted. A major finding of this research is that wagers of construction activities should be encouraged to use tine-lapse photograghy as a work simplification tool. This finding and ac explanation of the research is planned for broad dissemination among Indiane higiwey contractos;.

The report is subalted for the record and for scceptance.

Respectfully submitted,

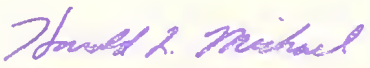

Harold I. Michael

Associate Director

ELN/Ig

Attachnert:

Copy:

F. L. Ashbaucher
W. L. Dolch
W. H. Goetz
W. L. Grecco
G. K. Hallock
R. Z. Harr

R. E. Har工
R. H. Earrell
J.A. Havers
V. E. Harvey
G. A. Zeonards
F. B. Kendenha1 1
R. D. Miles

C. P. Scholer

I. B. Seott

W. I. Spencer

H. ‥ J.Walsh

K. I. Woods

T. J. YcGier 
Digitized by the Internet Archive in 2011 with funding from

LYRASIS members and Sloan Foundation; Indiana Department of Transportation 
Plas 1 Report

TIE ABPLICATION OP TBR-LAPSE BZOTOCZAPHY IN HORT SDELIFICATIOA STUDIES OF COMSTRUCTEON OBMRATONS

\section{by}

Jimmy Alan Jecolson

Graduate Assigtent in Research

Jolnt Highway Research Project

File No: $9-11-4$

Project ?o: C-36-67D

Burdue University

Lafayette, Indiana

June 17, 1969 


\section{ACKNOWLEDGMENTS}

The, author wishes to express his sincerest appreciation to Dr. John A. Havers, Associate Professor, Construction Engineering and Management, Purdue University for his invaluable assistance in the study and for his critical review of the manuscript. Appreciation is also expressed to Professor William L. Grecco and Professor Robert W. Johnson for their review of the manuscript.

Acknowledgment is given the numerous representatives of the construction organizations and the Indiana State Highway Commission who made the study possible. Thanks are extended to Marian Zumwalt for her efforts in typing the preliminary and final drafts of this thesis.

I especially thank my wife Mary Ann for providing the needed moral support and for making it financially possible for me to study at Purdue University. 
TABLE OF CONTENTS

Page

LIST OF TABLES $\ldots \ldots \ldots \ldots \ldots \ldots \ldots \ldots \ldots \ldots \ldots \ldots \ldots \ldots \ldots \ldots \ldots$

IIST OF FIGURES $\ldots \ldots \ldots \ldots \ldots \ldots \ldots \ldots \ldots \ldots \ldots \ldots \ldots \ldots \ldots \ldots \ldots$

ABSTRACT $\ldots \ldots \ldots \ldots \ldots \ldots \ldots \ldots \ldots \ldots \ldots \ldots \ldots \ldots \ldots \ldots \ldots \ldots \ldots \ldots \ldots \ldots$

INTRODUCTION $\ldots \ldots \ldots \ldots \ldots \ldots \ldots \ldots \ldots \ldots \ldots \ldots \ldots \ldots \ldots \ldots \ldots \ldots$

WORK STUDY CONCEPTS $\ldots \ldots \ldots \ldots \ldots \ldots \ldots \ldots \ldots \ldots \ldots \ldots \ldots \ldots \ldots \ldots$

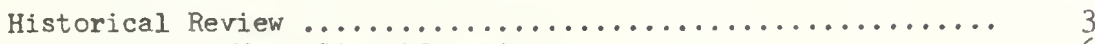

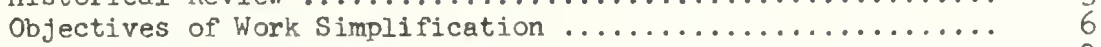

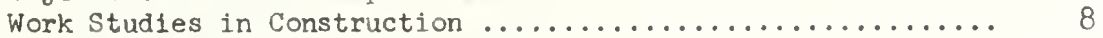

The Management Role ........................... 12

WORK STUDY ANALYSIS $\ldots \ldots \ldots \ldots \ldots \ldots \ldots \ldots \ldots \ldots \ldots \ldots \ldots \ldots$

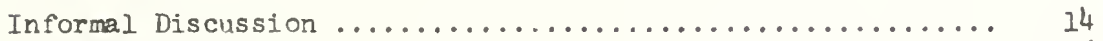

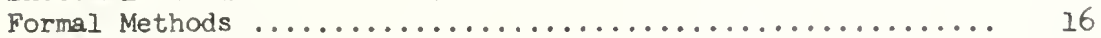

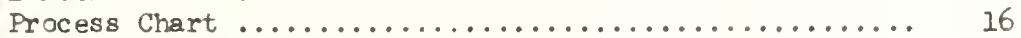

Crew Balance Chart ........................ $2 \hat{c}$

PLANNING THE STUDY $\ldots \ldots \ldots \ldots \ldots \ldots \ldots \ldots \ldots \ldots \ldots \ldots \ldots \ldots \ldots$

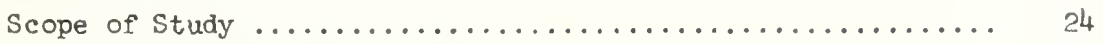

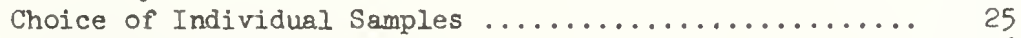

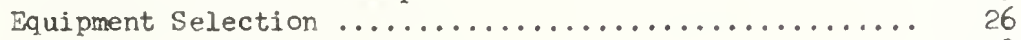

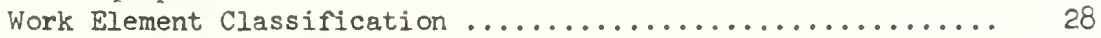

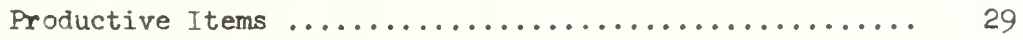

Productive and Nonproductive Items ............... 29

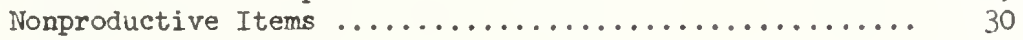

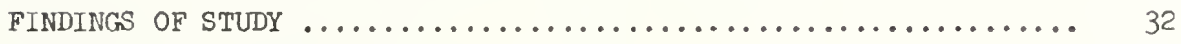

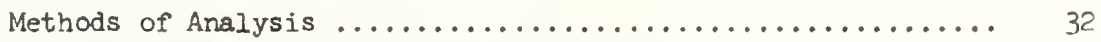

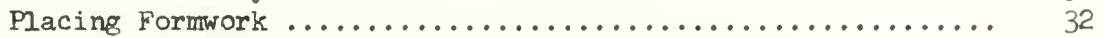

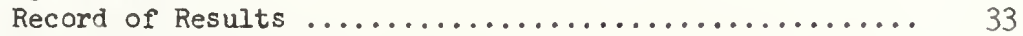

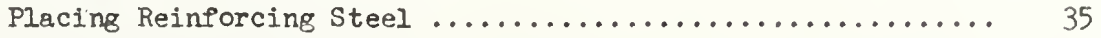

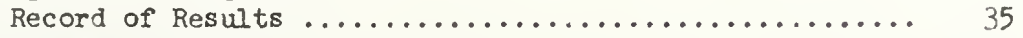

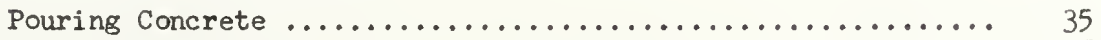

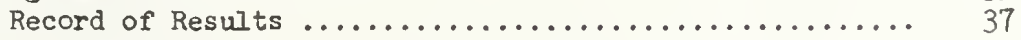


TABLE OF CONTENTS (continued)

Page

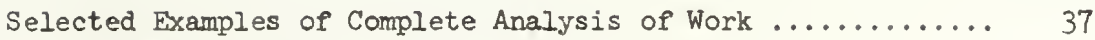

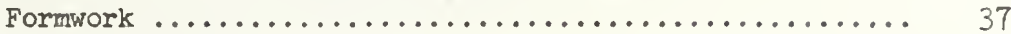

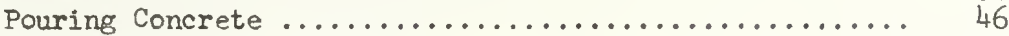

Placing Reinforcing steel .................... 49

CONCLUSIONS AND RECOMMENDATIONS $\ldots \ldots \ldots \ldots \ldots \ldots \ldots \ldots \ldots \ldots \ldots \ldots$

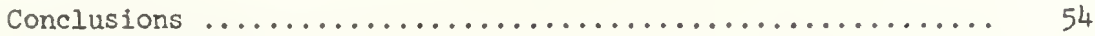

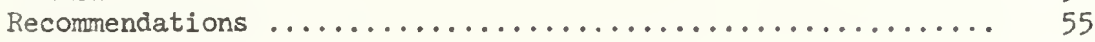

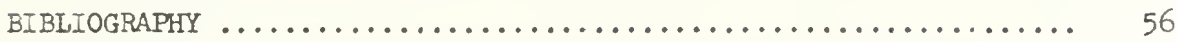

APPENDIX A: TIME-LAPSE PHOTOGRAPHY APPIICATION TO CONSTRUCTION METHODS STUDIES - A GUIDE MANUAL .................... 57

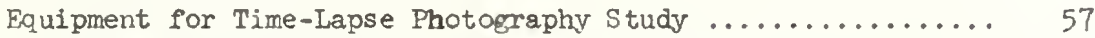

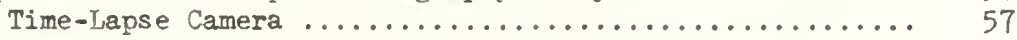

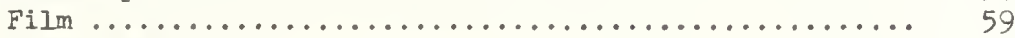

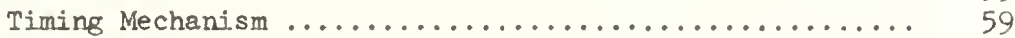

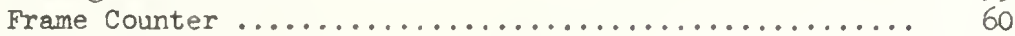

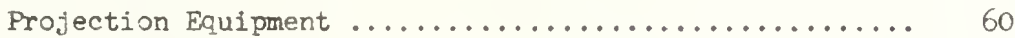

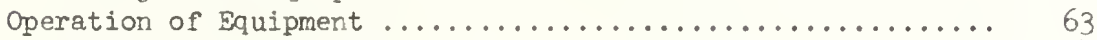

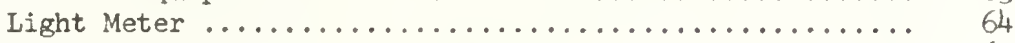

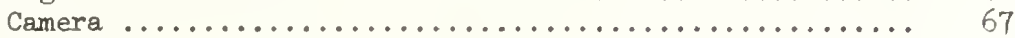

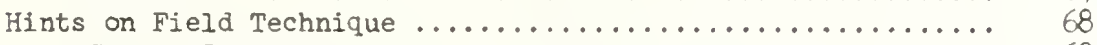

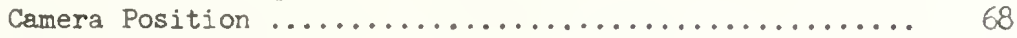

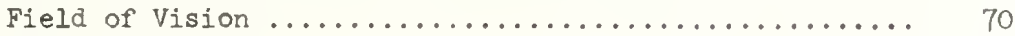

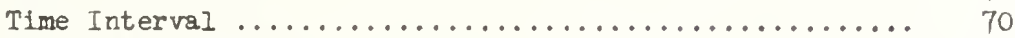

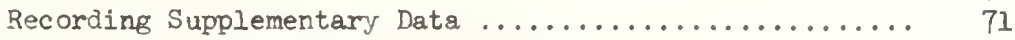

Work Simplification Analysis Techniques ............... 71

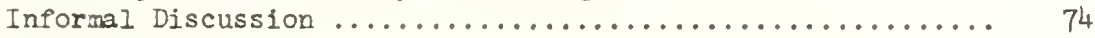

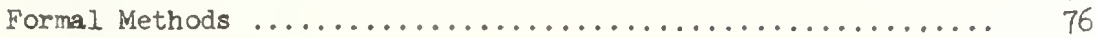

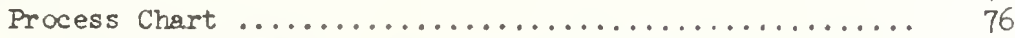

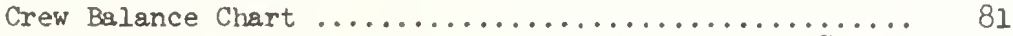

Example of Joint Use of Crew Balance Chart and Process Chart. 84

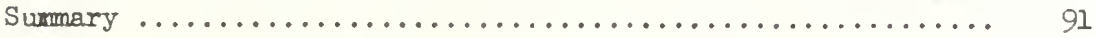

APPENDIX B: SUGGFSTED STEPS TO METHODS IMPROVEMENT ......... 92

APPENDIX C: A PARTIAI LIST OF EQUIPMENT SUPPLIERS ........... 94 


\section{LIST OF TABLES}

Table

Page

1. Process Chart and Process Time Chart Symbols ............ 19

2. Summary of Percentages of Time Spent on Various Activities

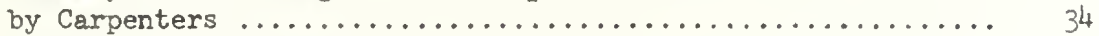

3. Summary of Percentages of Time Spent on Various Activities

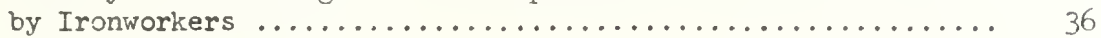

4. Productive and Idle Time for Laborers Vibrating Concrete

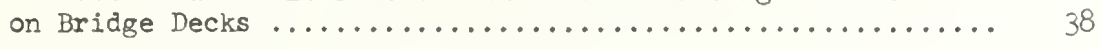

5. Productive and Idle Time for Machines Used in Concrete Pouring Operations ........................... 39

6. Process Chart Symbols ........................ 79 
LIST OF FIGURES

Figure

Page

1. Areas of Work Simplification $\ldots \ldots \ldots \ldots \ldots \ldots \ldots \ldots \ldots$

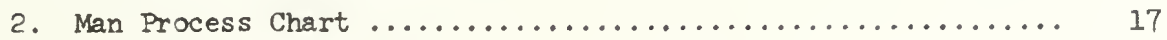

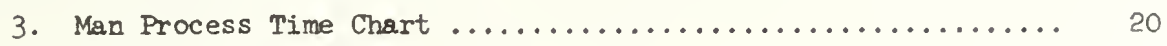

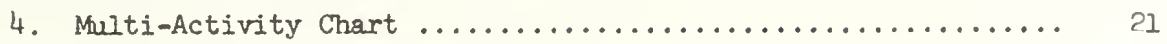

5. Crew Balance Chart for Carpenters ....................... 23

6. Photographic Equipment $\ldots \ldots \ldots \ldots \ldots \ldots \ldots \ldots \ldots \ldots \ldots \ldots \ldots \ldots \ldots \ldots$

7. Deck Form Plans .......................... 40

8. Man Process Chart for Carpenters .................. 42

9. Crew Balance Chart for Carpenters Using Original Method .... 43

10. Crew Balance Chart for Carpenters Using Revised Method ..... 45

11. Man Process Time Chart for Ironworkers .............. 50

12. Crew Balance Chart for Ironworkers Using Original Method .... 51

13. Crew Balance Chart for Ironworkers Using Revised Method .... 52

14. Photographic Equipment ........................ 61

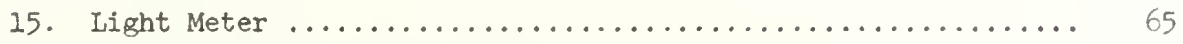

16. Camera Platform for Automobile .................... 69

17. Elements of Work Simplification $\ldots \ldots \ldots \ldots \ldots \ldots \ldots \ldots$

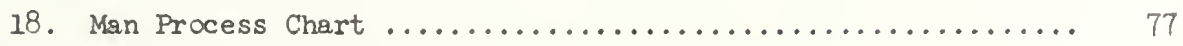

19. Man Process Time Chart ........................ 80

20. Murti-Activity Chart ........................ 82

21. Crew Balance Chart for Carpenters ................. 83 


\section{IIST OF FIGURES (continued)}

Figure

Page

22. Deck Form Construction .......................... 85

23. Process Chart for Carpenters ................... 86

24. Crew Balance Chart for Carpenters Using Original Method .... 88

25. Crew Balance Chart for Carpenters Using Revised Method ...... 90 


\section{ABSTRACT}

Jacobson, Jimy Alan. MSCE, Purdue University, June 1969. The Application of Time-Lapse Photography in Work Simplification Studies of Construction Operations. Major Professor: John A. Havers.

The purpose of this research was to study the use of time-lapse photography in work simplification studies of construction operations. It was hoped thet the usefulness of the method could be demonstrated to construction management, primarily through suggesting improvements which might help the industry to become more efficient. In addition, it was hoped that the experience thus gained by staff members and graduate students would make possible the inclusion of appropriate work study material in course work as a learning aid for future students.

Working through the Indiana State Highway Cormission with a group of Indiana bridge constructors, the operation of bridge deck construction was studied. The findings indicated that this construction operation did contain inefficiencies which warranted formal work simplification studies. Analyses are included in the research report to support this conclusion.

In a direct sense, the goal of providing concrete suggestions which would improve the efficiency of construction operations was not reached. Rather, it was concluded that managers should be encouraged to apply time-lapse photography as a work simplification tool to their particular construction operations. Generalized work simplification findings are 
of questionable value to construction managers because of the changing nature of their work. However, specific applications of work simplification techniques can be of substantial benefit to each construction organization. 


\section{INTRODUCTION}

Work simplification is the analysis of a task from all aspects so that it may be done better, with less effort, and with a lower expenditure of time and money. (10) This definition provides formal recognition of man's continuing efforts to find easier methods to do those tasks which are required of him. In order to implement work simplification studies, simple techniques are needed which will enable management personnel to isolate the weaknesses of existing work methods and subsequently seek improvements. It is neither necessary nor possible for each manager to be a specialist in the field of work study, but this need not preclude his use of a clearly-demonstrated analytical techniaue.

This paper describes the use of time-lapse photography in work simplification studies of selected construction operations. " Work simplification is not a new concept to the construction industry, nor is the use of time-lapse photography for recording work studies. Speaking in general, however, the construction industry has been slow in applying these techniques, as well as other relevant principles of "methods engineering." (3) The traditional viewpoint, still supported by many construction managers, is that construction work is not sufficiently

\footnotetext{
a Time-lapse photography, as defined here, consists of time-sequenced pictures separated by a precise time interval, (usually 1,2 or 3 seconds) and continued over long periods of time. Cumulative elapsed time between recorded events may then be measured directly from the film.
} 
repetitive to merit a scientific approach to work study. Nevertheless, this study was undertaken with the conviction that work simplification is in fact applicable to construction work. Time-lapse photography was selected to demonstrate its potential as a management tool for implementing such studies.

This research project was financed as a Highway Research Project under the joint direction of Purdue University and the Indiana State Highway Commission (ISHC). Although its field research was confined to the observation of bridge deck construction, this is not intended to suggest that the time-lapse technique is Iimited to a particular field of construction. In addition to demonstrating the usefulness of the methods to constructors and helping them to improve the efficiency of their operations and thereby lower costs, it is hoped that the experience gained by staff members and graduate students will make possible the inclusion of such material in course work to provide continuing experience for other students. 


\section{WORK STUDY CONCEPTS}

\section{Historical Review}

F. W. Taylor (1856-1915), often referred to as the "Father of Scientific Management", was the originator of the Differential Piece Rate System. (12) This system compared the actual production of workers against a set of production standards. These standards, in turn, were obtained by recording the performance of the most productive workers. It is to Taylor and subsequent investigators that modern techniques of work simplification owe their origin. Much of the early criticism of work study, or time study as it was then known, grew from the undue hardship which was placed on slower workers by Taylor's and similar systems. Even today, managers may find that labor disapproval is a major obstacle to the use of work simplification studies. Such fears on the part of labor are usually the result of manament's failure to convey to all concerned the true scope and objectives of a work study.

The work of Frank and Lillian Gilbreth marks another milestone in the development of work simplification. They were the first to utilize motion picture records for work simplification, and it is their work which has led to the use of time-lapse photography as discussed here. (12) Although conventional motion pictures were initially used to record the work activities, it was soon realized that adequate records could be obtained with much less detailed coverage. This new concept, called 
"micromotion study" by the Gilbreths, involves the use of motion pictures in conjunction with a timing device. (12) The manufacturing industry has found micromotion study valuable, not only in work simplification, but also in teaching, safety studies, and descriptive presentations. (10)

It is interesting to note that the early work of such people as Taylor and the Gilbreths centered on construction tasks. In fact it was this work that subsequently led to their better-known achievements in industrial engineering. As early as 1918 Daniel Hauer was plagued by the basic need "to find the best and cheapest way to accomplish an item of construction work and provide the means for doing it in this fashion." He established methods to perform these tasks but, fifty years later, few are practicing what he learned and reported; indeed, few persons have any real understanding of what he was writing about. The construction manager of today continues to use almost the exact words that were used fifty years ago -. "My work is different:" (10) It is admittedly true, as it was fifty years ago, that the end products of nearly all construction jobs are somewhat different. This non-repetitive feature is a favorite argument for construction managers who say "work simplification won't work for me." Although appealing on its surface, the argument has its fallacy. Conceding that differences in the end product do exist, it does not necessarily follow that the work components which make up the finished products are different. Viewed at this level, it is much less logical to assert that construction work is non-repetitive. 
As an illustration of this point, consider the design of a modern grade separation structure. Within a delineated geographical area, usually a state, there is a degree of standardization in bridge design. If the bulk of a contractor's work consists of such similarly-designed bridges, it is inevitable that he will repeatedly perform the same work activities. A similar situation exists for the contractor who is involved in the construction of a multi-story building. Here, as in the example just presented, work activities will be performed repetitively as the crews move successively to higher stories of the building. Even if an entirely different design and its related construction techniques are introduced for a facility, various individual work assignments will be repeated many times before the structure is completed. The units of buildings are rabricated and set in place by the same trades and by methods which remain essentially unchanged, hence the claim that construction work is non-repetitive is not a defensible one. A crew of carpenters which hangs joists on a system of beams, using wire hangers, and then floors the jolsts with plywood on bridge after bridge is repeatedly performing a limited number of basic tasks.

Some construction managers have become aware of the repetitive nature of basic construction tasks, and in a few instances have initiated work simplification studies using time-lapse photography. Formal research in this area has been described by Professor Henry $W$. Parker of Standord University in a report entitled "Methods Improvements Techniques for Construction and Public Works Managers." (10) 


\section{Objectives of Work Simplification}

From the definition of work simplification, the objective of a work study is to improve the sequence of work so that it is done with better quality, in less time, at a lower cost, and with less effort. The analyst will find that the efforts of work study center around one or more of four areas. Figure $I$ shows these areas of work simplification and their interrelationships. Pre-planning is an important area and, unfortunately, is probably the least recognized element of efficient work. Included in pre-planning is the pre-instruction of workers and proper scheduling of material, equipment, and labor resources. Many times, during analysis, it will become apparent to the manager that preplanning was either inadequate or neglected entirely. The identification of a work task which has an obvious repetitive nature but whose work crew does not utilize a work cycle is a certain indication of such a lack.

Improvement of techniques is self defining. The guiding philosophy is that no work method is the best, and a better method can always be found. (2) Closely related are the balance of work forces and efficiency of interrelationships. The balance of work forces is a measure of the allocations of material, equipment, and labor resources. It is equaliy bad to have either too many or too few resources, and it is important that resource requirements be carefully considered both before and after changes in methods. An evaluation of the efficiency of interrelationships includes the operations of each member of the work force and the interactions and restrictions of these operations. Many times efficiency can be improved simply by a change in sequence to eliminate conflicting operations. 


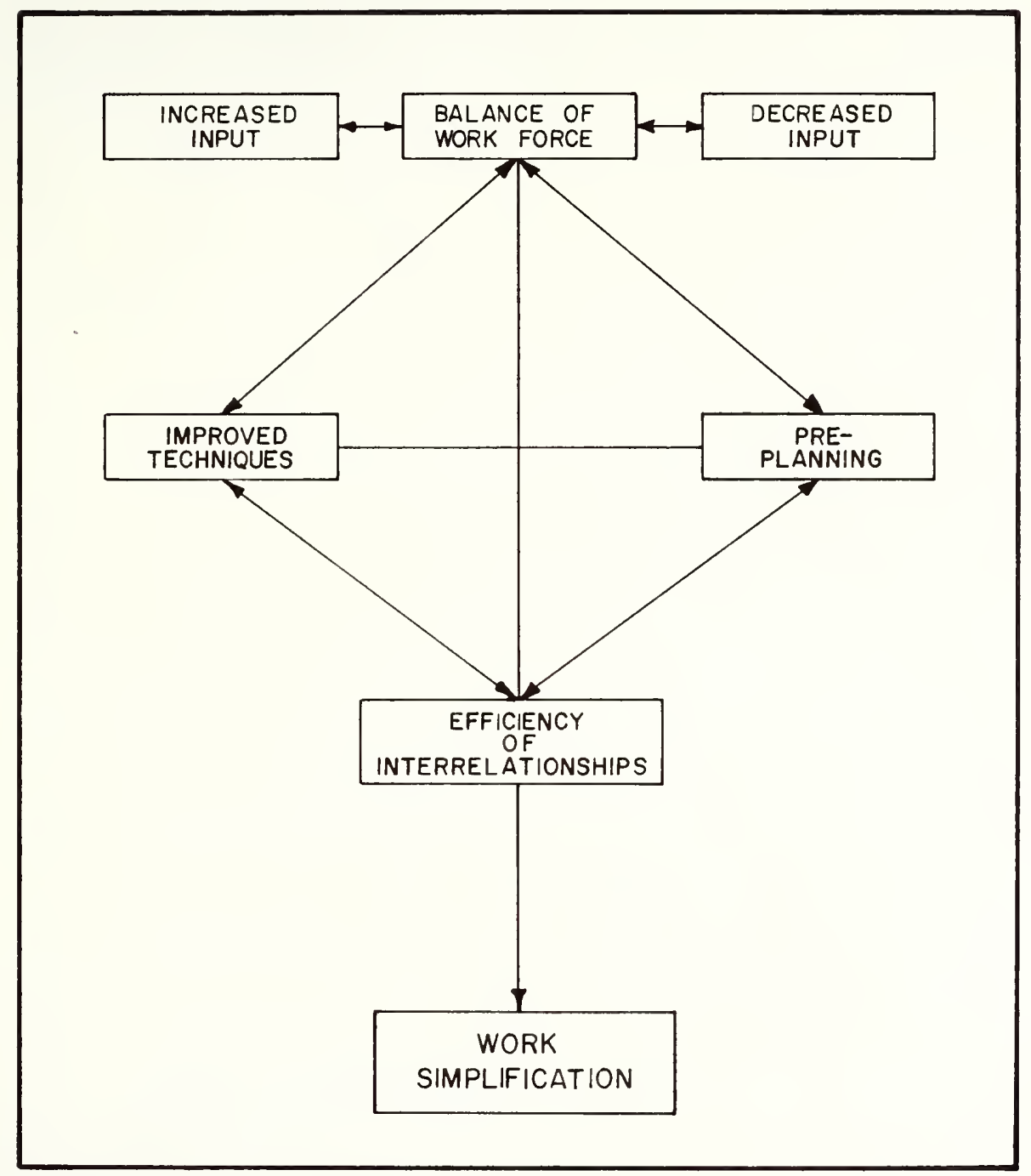

Figure 1. Areas of Work Simplification 
When work simplification is undertaken, the analyst should be aware of the four areas of possible improvement, as indicated in Figure 1. The more promising areas can then be studied. During the review of a work sequence, the answers to the questions listed below will be helpfur in fully evaluating the worth of each portion of the task.

1. What is the purpose of each activity (need it be done at all)?

2. Where is it done (place)?

3. When is it done (sequence)?

4. Who does it (person)?

5. How is it done (means)?

The persistent application of these questions, and the answers obtained thereto can help to lead the analysis of work toward rational simplifications and improvements. (12)

\section{Work Studies in Construction}

Work simplification, when applied in construction work, will be more valuable if the special needs of the industry are acknowledged when designing the study system. The requirements which should be considered during the implementation of a work program are listed below: (4)

1. The information obtained should be readily convertible to tangible data on time and cost.

2. The operation should be completely documented so that varying work conditions may be considered in the analysis.

3. The technique should include a practical means for observing and recording both the individual and collective actions of the work force.

4. The technique should permit the evaluation of tentative changes in methods, and should supply factual justification for methods actually adopted. 
5. An effective means of presenting facts and findings to supervisory personnel should be available.

6. The system should include readily available and fullydocumented data files for past operations.

The primary step in any work study is to observe and record the activities of the men and machines so that these operations and their interrelationships can be analyzed at a later time. The many methods which may be used to record data can be grouped into three categories; direct observation with a written record, timed observation (observer with stopwatch) with a written record; and motion picture observation and record.

To be effective, a work study must record in detail the activities of each worker and machine in the work force. A single observer can watch only one man or machine with confidence as to the results. When a crew consists of more than one worker or machine, direct observation and timed observation require more work study personnel. As an alternative, it is possible for a single observer to record sequentially the activities of each crew member over a series of repetitive work cycles. In applying this method, it is implicitly assumed that the resulting data can be combined into a valid composite of the actual work cycle. Since there can be subtle variations in construction work cycles, the true interrelationships among workers and machines can be last by this assumption.

The most efficient recording method in construction work is timelapse photography. In fact, it appears that time-lapse is the only method which can physically and economically do the job. A work study, no matter how many dollars it saves, is useless unless the cost of 
performing it is less than the savings which it generates. To obtain the equivalent of a photographic record by applying the direct observation techniques, it would be necessary to assign an observer to each worker. It is rare that ultimate savings will ever warrant the costs of such a method except on the most repetitive tasks.

On the other hand, the cost of time-lapse photography is Iow. The initial investment for equipment will range from $\$ 1,000$ to $\$ 2,000$, a cost which is insignificant when allocated over many potential years of work studies. The operating costs consist of film and film processing, and are low because the details of work methods can be adequately recorded at a film speed much lower than that of conventional motion pictures. Time-lapse pictures are generally taken at a speed of one frame every three seconds (20 frames per minute or 1200 frames per hour). A standard 100 foot roll of film will last three hours and twenty minutes as opposed to 4 minutes and ten seconds at standard speed. (10) The total cost of a 100 foot roll of film is approximately $\$ 15.00$ in the $16 \mathrm{~mm}$ size and $\$ 5.00$ in the $8 \mathrm{~mm}$. The two sizes of equipment are discussed in detail in Appendix A.

No other method of recording provides as clear and concise records as does time-lapse photography. Every detall of the movement of men and machines is shown, and the record is indisputable. In subsequent analysis of job performance, evidence of this type may prove more convincing to the job foreman or supervisor than the unsupported opinion of his superior. 
The complete film record will also reduce the "sampling" problem inherent in a study of construction work. The manager is usually unable to pre-determine with any confidence the specific work operations which should be studied, but with a complete record the initial analysis can be extended to include every part of the work cycle. It can subsequently be refined, level by level, to concentrate on the more deserving areas of the work. Without a complete record, the areas of study on a task must be initially selected at random and subsequently refined over a series of work samples. The time required for this can be critical in a situation where subtle changes may make improvements obsolete by the time they are developed and initiated.

Filmed records can be easily documented for future reference. Many times work requirements are very similar to what has been done in the past. If the interim period has been lengthy, the previously applied methods and techniques may have been forgotten by the supervisors, foremen, and laborers. A review of filmed records of previous work can then save valuable time and cost. Sequences showing unusual job techniques or the operation of complicated equipment can also be useful in the training of personnel.

The analysis of work simplification is the most difficult phase to accomplish. Time-lapse offers a substantial advantage in that the job operation can be reviewed many times. Also, because of the opportunity for repeated reviews, the analyst is relieved of the burden of making instantaneous judgments about the activity of the subjects. The analyst can gain better confidence in his understanding of the flow and sequencing of the work, and the reliability of the data taken from the 
film is better. The data collection and data analysis phases are completely separated, as they should be. This separation permits the methods analyst to do his work at the proper time and place. The most productive observations and improvements will occur when the analyst is thinking clearly and objectively. (10) The typical atmosphere of the job site is seldom as conducive to objective thought as is the manager's office.

\section{The Management Role}

From reviewing the history and development of work simplification one might be tempted to conclude that construction in general has failed to recognize the applications of modern work study. This would be a gross over-simplification, and there is no intent to suggest that construction magers have completely overlooked the importance of organization and planning. In fact, the growing acceptance and use of techniques such as CPM (Critical Path Method) and PERT (Program Evaluation and Review Technique) provide support to the thesis that management is not completely adverse to organization. (10)

Nevertheless, although all construction organizations must necessarily use some form of over-all management very few extend adequate magement control to the level of the individual crew. Many times laborers or semi-skilled workers are left to supervise and plan the daily work schedule. This policy will generally lead to increased costs since. While some crew supervisors may have excellent management ability many do not. The basic responsibility rests with construction management, and these persons must be encouraged to re-evaluate their present management techniques. 
In suggesting that the interests of construction management should be extended into the supervisory levels, it is not proposed that the imagination and initiative of the worker be discouraged; in fact, the opposite is the goal. (10) Employee involvement in decisions has been shown to lead to increased interest and productivity. (6) Case studies have shown that men who are well acquainted with their work can, given guidance and opportunity, devise new and better methods for their jobs. (10) There is no substitute for the resourcefulness of men on the job, but management should aid and assist the workers in planning and organization. Otherwise they may lead in divergent directions.

The role of management in work simplification must be understood by labor. who often has a fear of any formal study of work cycles and methods. These fears stem from the unfavorable experiences of the past, when early techniques and philosophy often abused workers. It is important that labor realize that the final outcome will most probably be the use of new methods requiring less physical effort. (10) 


\section{WORK STUDY ANALYSIS}

The technique of analysis is the most difficult part of work study to quantify and the most difficult skill for the analyst to acauire. It would be convenient if it were possible to formulate a check list which a manager could use for his analysis. However, it is impractical to use such a "cut and dried" approach when evaluating the tasks of construction work. The work is not so analytical that it can be defined without making judgment decisions. This does not, however, preclude the use of a plan of attack when initiating a study.

\section{Informal Discussion}

The informal discussion of work sequences is probably the single most productive analytical technique for construction work. (10) The time-lapse technique lends itself to group discussion, because the entire group can see the filmed work scene and discuss the action as if it were actually occurring before them.

Informal discussion improves the two-way line of communication between management and labor. Continuing and frequently subtle changes in specifications, construction techniques, and personnel make it difficult for construction management to remain conversant with actual conditions in the field. In fact, one of the favorite criticisms of suggestions connected with work simplification is "They just don't know what is happening out here." At times this type of criticism is merely a general 
resistance against an unfamiliar situation, but at other times it is valid and reflects the fact that management is inadequately informed. Labor too, is often uninformed; in the hurry of the fob site, instructions to labor may be totally inadequate. (10) Informal discussion bypasses these two communication gaps and, by including managers, engineers, foremen and even workmen in the planning process, the product auality of work study is improved.

The best atmosphere for conducting an informal study is a relaxed and comfortable one. It is extremely important that all groups feel at ease and unhurried, and it might be necessary to separate the top management group from that of foremen. When the group members are concentrating exclusively on the study subject, they will be more productive in their thoughts.

The group discussion should begin with a broad review of the work sequence. This step is particularly important when the time-lapse system is new and management is unaccustomed to fast movement of the film. From this initial review the analys is should be refined, level by level, following the most productive path. As the analysis reaches the finer levels of refinement, the group may divide into smaller groups or individuals for further study of the work.

The group leader should try to hold the discussion at each level until a consensus is reached concerning the problem areas and the path of succeeding analysis. This will not always be possible, but it is important to attempt to obtain agreement so that subsequent arguments will not defeat the purpose of discussion. 


\section{Formal Methods}

Although much productive information can be realized from informal discussion. formal techniques must also be used. A significant amount of time can be saved if the discussion group leader has already chosen the portions of the work which warrant detailed analysis. To enable him to do this, a method is needed to evaluate the information which is obtained from the preliminary analysis.

There are many graphical methods of tabulating and analyzing work simplification data. These methods are useful in presenting data and are valuable as tools for use during all levels of analysis. Two of the more popular methods are discussed in the next section.

\section{Process Chart}

One tabular method for analysis of work is the process chart shown in Figure 2. The man process chart is a symbolic and systematic presentation of the method of work (series of operations) when movement from workplace to workplace is required. (7) It is an excellent device for presenting the pertinent facts concerning the job. From the analysis of existing conditions, theoretical charts can be constructed. These can be used to assist in planning and as a presentation of proposed method changes.

The graphic presentation of the chart is an excellent "selling" feature. Too often suggestions from either management or labor are forgotten merely because the other disagreed initially. Charts which illustrate both present and proposed methods, with improvements well annotated, provide a record for more detailed examination. Facts presented in writing are generally more acceptable than verbally-expressed ideas. (7) 
OF__ Carpenters

DATE LOCATION Interstate 70

CONTRACTOR Jones, J. BY j.8.h. FILM NO. B-40

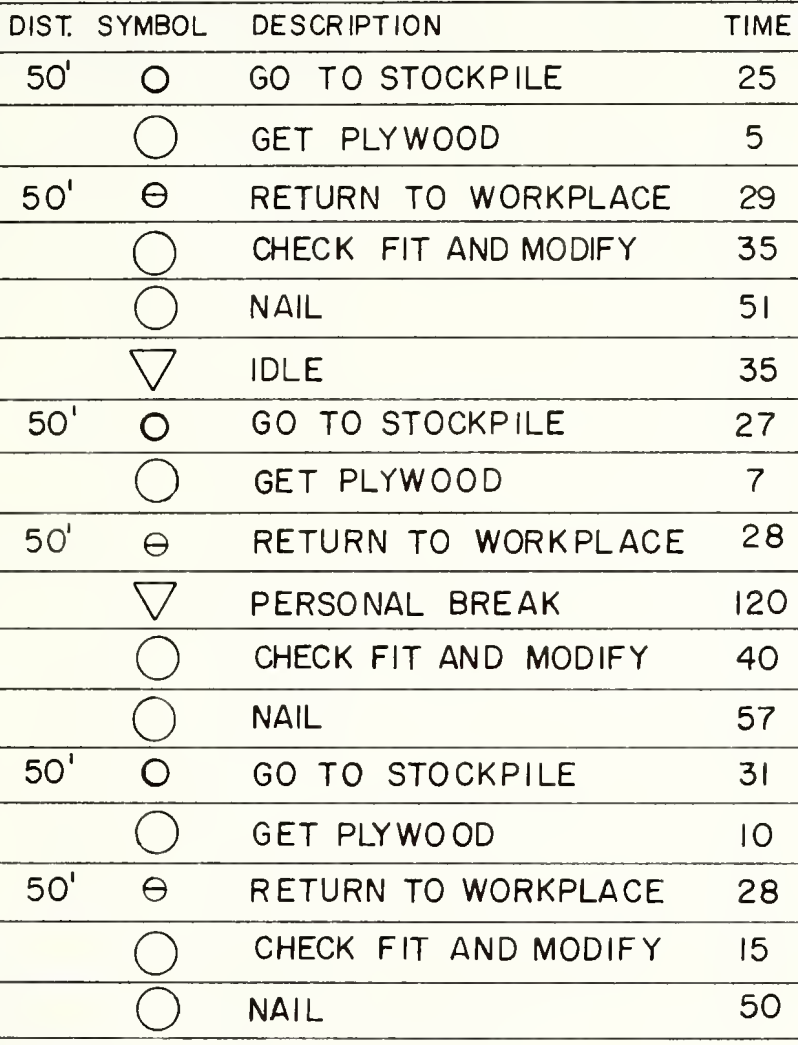

Figure 2. Man Process Chart 
One recommended system of symbols to identify related activities on process charts is shown in Table 1 . Both geometric symbols and time symbols are shown. The time symbols are used on a slight modification of the basic process chart which is known as the man process time chart. It differs from the basic process chart by making the length of each symbol proportional to the time period over which the activity occurs. Each line of the chart thus represents a definite amount of time. (7) A process time chart for the work previously illustrated in Figure 2 is supplied as Figure 3. Both charts are useful for analysis. The basic process chart is more compact, and is probably the best choice for simple tabulation and presentation of activity times and percentages. The salient advantage of the process time chart is the ease of tabulating data. The times of each activity are merely taken from the frame counter and marked directly on the chart. The process time chart also gives excellent representation of the interrelationships of the activities of men and machines. Since each element of the crew is plotted to the same time scale, interrelationships can be compared along a horizontal Iine on the chart. (10)

A single process chart or process time chart which presents the activity of more than one man or machine is often referred to as a multiactivity chart. Other names such as multi-man or man-machine are also used, but have essentially the same meaning. The multi-activity chart supplied as Figure 4 illustrates the interrelationship among workers.

The process chart is an excellent tool for planning analysis. Since the lengths of all the work cycles are recorded, estimates of time needed to do each task can be established. The planner can then rearrange the 
Table 1. Process Chart and Process Time Chart Symbols

\begin{tabular}{|c|c|c|c|}
\hline $\begin{array}{l}\text { Geometric } \\
\text { Symbol }\end{array}$ & $\begin{array}{c}\text { Time } \\
\text { Symbol }\end{array}$ & Name & Activity Represented \\
\hline & & $\begin{array}{l}\text { Work of the } \\
\text { trade. }\end{array}$ & $\begin{array}{l}\text { Doing something at one work } \\
\text { place. }\end{array}$ \\
\hline & 电册 & $\begin{array}{l}\text { Walking without } \\
\text { load. }\end{array}$ & $\begin{array}{l}\text { Change in location without } \\
\text { load (taking more than one } \\
\text { step). }\end{array}$ \\
\hline$\theta$ & $\notin \infty 8$ & $\begin{array}{l}\text { Walking with } \\
\text { load. }\end{array}$ & $\begin{array}{l}\text { Change in location with load } \\
\text { (taking more than one step). }\end{array}$ \\
\hline & & Delay (idle). & $\begin{array}{l}\text { Held up by other tradesmen, } \\
\text { waiting for tools and equip- } \\
\text { ment, idle for no reason. } \\
\text { personal delays. }\end{array}$ \\
\hline & DID & Planning. & $\begin{array}{l}\text { Receiving instructions, } \\
\text { planning, or discussing lay- } \\
\text { out. }\end{array}$ \\
\hline & & Seeking. & $\begin{array}{l}\text { Reaching or searching for } \\
\text { materials, tools, or equip- } \\
\text { ment. }\end{array}$ \\
\hline & & $\begin{array}{l}\text { Work of another } \\
\text { trade. }\end{array}$ & $\begin{array}{l}\text { Work which should be done by } \\
\text { another tradesman. }\end{array}$ \\
\hline
\end{tabular}




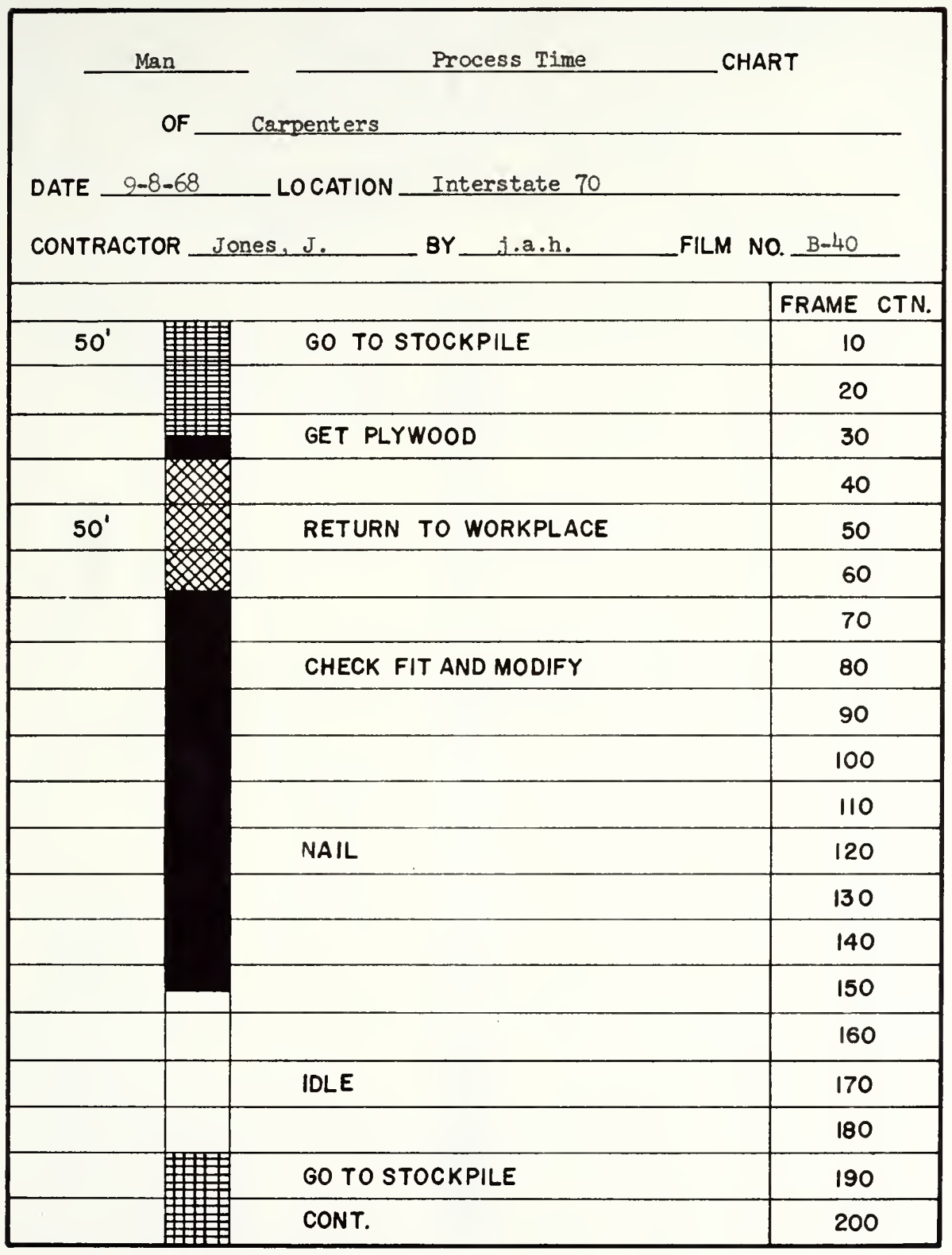

Figure 3. Man Process Time Chart 


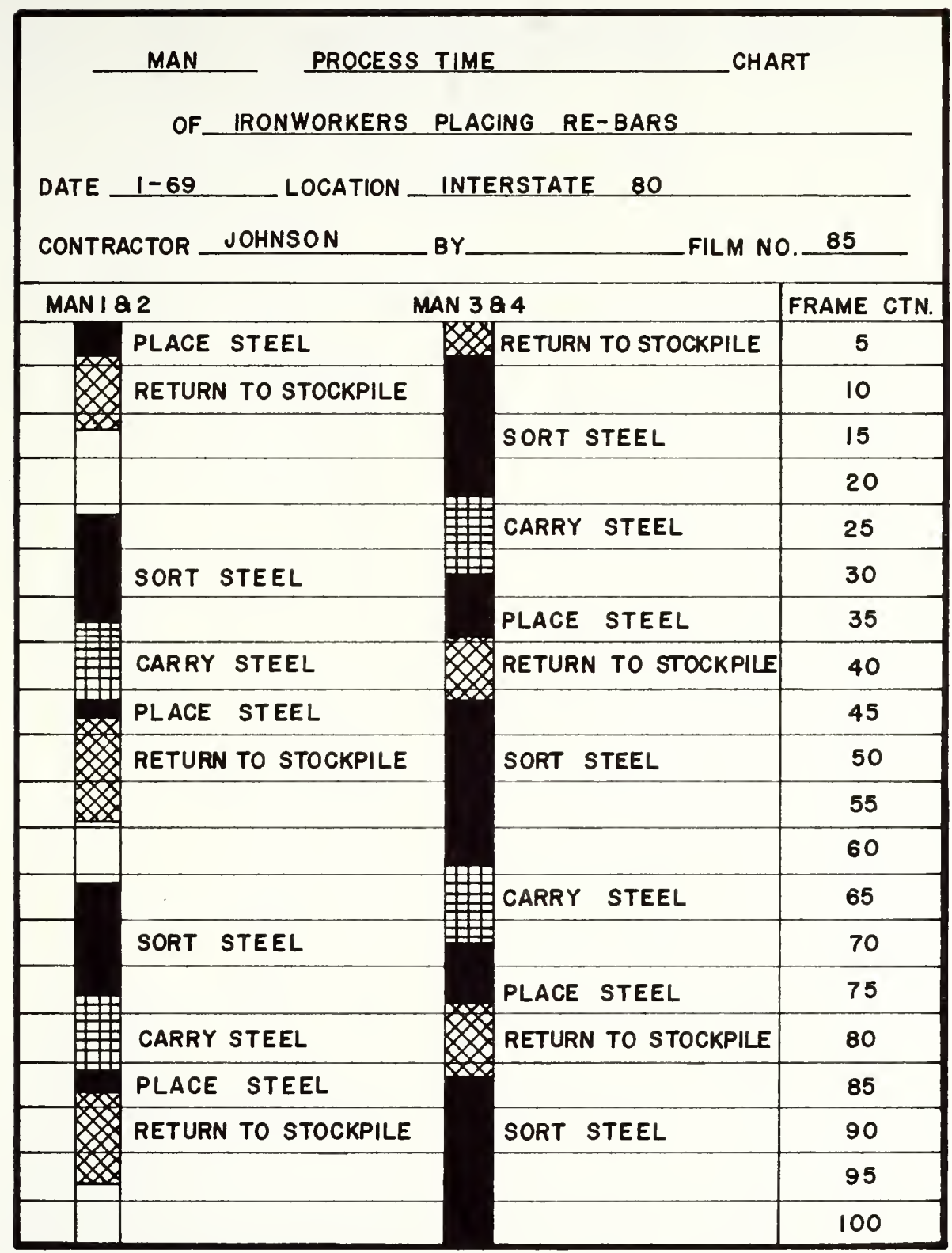

Figure 4. Multi-Activity Chart 
cycles of the work force so that the interrelationships among them can be as efficient as possible.

\section{Crew Balance Chart}

A chart very similar to the process chart is the crew balance chart, shown in Figure 5. This presents the activities of the work force for one complete work cycle, and can be used in conjunction with the process chart. The process chart is then used to record and analyze, and the crew balance chart is used as a work sheet to revise and present the new methods. 


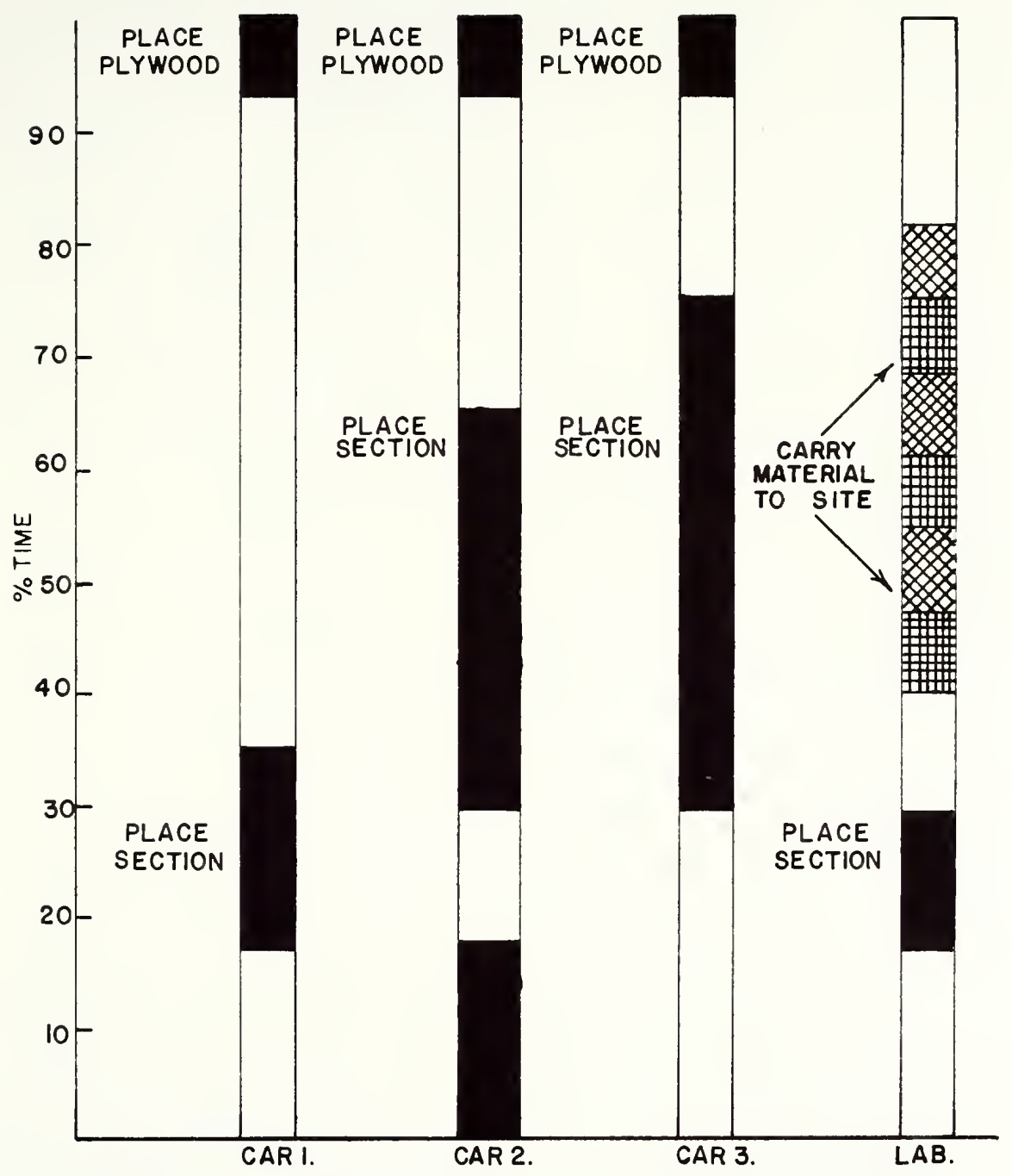

Figure 5. Crew Balance Chart for Carpenters 
PLANNING THE STUDY

\section{Scope of Study}

Since the study was sponsored in part by the Indiana State Highway Commission, it was possible to study concurrently the work of several contractors involved in highway construction in Indiana. ' There were both advantages and disadvantages in working through the I.S.H.C. rather than directly with the contractors. It was desirable to study and compare the work of several organizations which were involved in essentially similar work, and the engineering organization of the I.S.H.C. provided valuable guidance as to when and where the various types of work would occur. The major disadvantage was a lack of a direct involvement on the part of the contractor's personnel. The subsequent analysis would have been more meaningful if the construction managers had become more involved in this phase.

The first step in planning the research was the choice of a subject for study. If a construction manager were to make such a choice, he would be expected to choose an area where costs were high or difficult to control. This same policy was used in the selection of a subject for the research project. Bridge deck construction was selected for study after discussions with representatives of the I.S.H.C. and managers of

a

1. J. L. Wilson Co., Inc.

2. Rieth-Riley Construction Co.

3. R. L. Schutt Co., Ine.

4. Smith \& Johns on Construction Co. 
the construction organizations; the latter group felt this was a particularly important area, in light of current difficulties in estimating and controlling deck costs.

Construction of bridge decks as defined here included the operations of building forms, placing reinforcing steel and pouring concrete. The setting of beams was omitted. To narrow the scope of the study and to make the comparison of data from job to job as valid as possible, the structures used for sampling were all of the same basic design .longitudinal welded girders with a one-way reinforced concrete slab.

\section{Choice of Individual Samples}

In choosing each cycle, an attempt was made to avoid imposing any bias on the final results. No pre-evaluation of the work at a site was made before sampling began. Because of the varying schedules of the contractors, it was seldom necessary to make a prior choice as to what site would be sampled on a given date. Once this choice was made, the only requirement was to obtain an equal number of samples of the various types of work by each contractor. After arrival at the work site, the photographer attempted to choose a work force that would be in action for at least $1 \frac{1}{2}-2$ hours. It was felt that representative data would be obtained within this period.

Formal analytical procedures to determine the minimum number of work cycles for various levels of statistical confidence were not applied. Although definite cycles could be established for each task, there were still variations in the methods actually employed. Because of these variations, qualitative judgment was used to arrive at the necessary number of work cycles for each sample. 


\section{Equipment Selection}

Since it had already been agreed that time-lapse photography would be used to record the field data, the next step involved the selection of photographic equipment. There are many suitable systems available, and a complete discussion of the various choices is included in Appendix A. The equipment used in this study is described below. (See Figure 6.)

A Kodak K-100 16 mmera was selected; this had a spring driven motor and was operated in the single frame mode by an external release lever. The Sam Berthiot zoom lens used on the camera had a focal length range of 17.5 to $70 \mathrm{~mm}$ and incorporated a through-the-lens viewing system. This viewfinder showed the image as it would appear in the finished film.

For time-lapse photography, color film is almost a necessity. Without color reproduction it is impossible to identify individual men unless their faces are visible, and the resolution of all details is much better in color. In this project, where all pictures were naturally lighted in the daytime, Kodachrome II daylight color film was used. Other films are available to take satisfactory pictures in virtually any lighting condition.

A battery-powered mechanical timer was used to regulate the camera. A small, 24 volt constant-speed motor was used to drive a cam which actuated micro-switches. These switches controlled a 24 volt solenoid which was linked directly to the camera. A power pack consisting of four dry-cell batteries provided power for the system. Included in the timing mechanism was a digital counter that registered each exposed frame. 


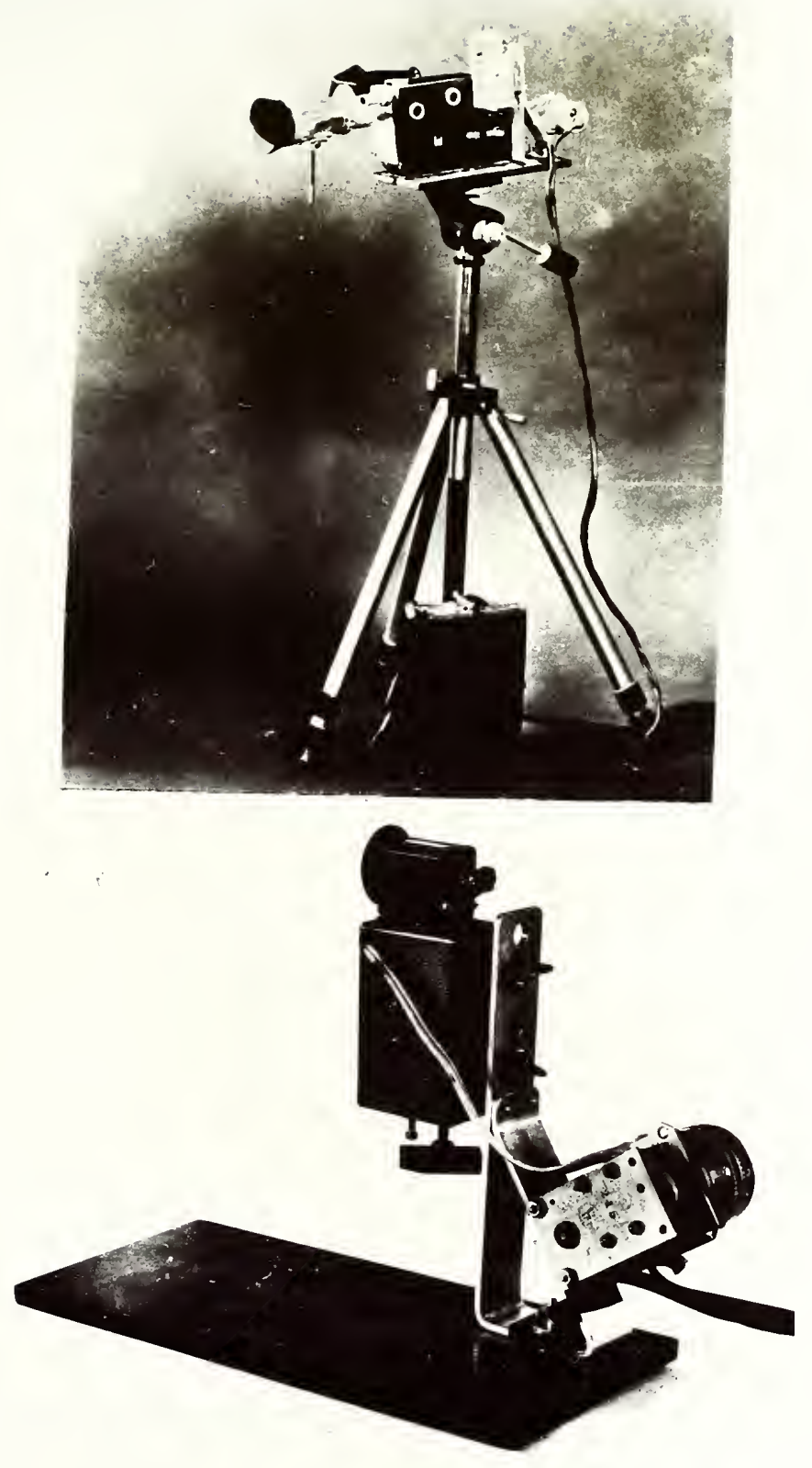

Figure 6. Photographic Foripment 
The projector was a Kodak Analyst which had been modified by L-W Photo Products Co. to permit either forward or reverse operation at speeds as slow as six frames per second. The shutter type mechanism on the projector contributed to the difficulties experienced while reviewing films at this speed. On this basis, it is recommended that a projector be of the prism operated type, with a speed capability of one frame per second.

\section{Work Element Classification}

A system of work elements must be defined so that the special characteristics of the work, its sequences and its tasks will be adequately recorded. Here use was made of a previous study of construction work, wherein the variables of workers, surroundings, tools, and equipment were considered over several trial studies and the work elements defined. (1) The work elements chosen for this study were:

Productive items
(1) Work of the trade
(a) Work of another trade
(3) Walking with load

Productive and nonproductive items

(4) Receiving instructions

(5) Reaching or searching for materials, tools, and equipment

(6) Planning, discussing, and layout

Nonproductive items

(7) Held up by other tradesmen

(8) Waiting for materials, tools, and equipment

(9) Walking unloaded

(10) Idle for no apparent reason

(11) Personal delays

${ }^{a}$ See Appendix A for further discussion of equipment. 


\section{Productive Items}

These are items or types of work that contribute directly to the final output of the product. As such, they can be considered as necessary to the performance of the work.

Work of the Trade. In each instance the man must be performing the work required of his trade. The man should be at a work station or within a limited work area. If the man moves away from the area he should be classified under another activity.

Work of Another Trade. The man must be performing work other than that required by his trade, or included within the agreement of his union. Such work would normally be done by another tradesman.

Walking with a Load. Under this classification the man must be walking, and must be carrying some item of material or equipment.

\section{Productive and Nonproductive Items}

These are items or types of work which include both productive and nonproductive work. The items are generally necessary, but would be less disruptive to the work cycle if done at other times. The decision as to the amount of work in each category is an arbitrary one.

Receiving Instructions. The man being observed must be receiving instructions from one of his superiors. Only when it is noted that a superior is actually talking to a man, group of men, or pointing to something, or in some manner appearing to discuss the work or method of work, should the time be recorded as receiving instructions. If the workmen are discussing the work themselves, the time would be recorded under a different classification. 
Reaching or Searching for Materials, Tools, and Equipment. The man must be reaching or searching for materials, tools, or equipment that are within easy reach. If he must walk further than a few steps the activity would not fall in this classification.

Planning, Discussion, and Layout. In each instance the man must be engaged in planning, discussing, or layout activities pertaining to the work. The planning or discussion of work is carried on between the working men, and does not involve a superior.

\section{Nonproductive Items}

These are items or activities performed by the worker which are not productive. The man is generally doing nothing of a work nature and is not contributing to the end product. In essence, the man may be called idle. The objective of this broad heading is to include the various sources or reasons of nonproductivity. By having classifications within the nonproductive category, one is able to direct attention to various fields where corrective action could or should be undertaken.

Held Up by other Tradesmen. The man must be held up or delayed because of another tradesman. He is unable to perform his task and must wait idly by while some other tradesman works.

Waiting for Materials, Tools, and Equipment. Under this classification the man must be waiting for materials, tools, or equipment. He is unable to continue his work because the required articles are not present. 
Walking Unloaded. Under this classification the man must be noted as walking without carrying materials, tools, or equipment. He may be walking to get materials, tools, or equipment, or to change the working position, or just to "kill" time.

Idle for no Apparent Reason. This classification includes standing idly around, or a discussion which obviously is not about the work. The men could be working, but actually are not.

Personal Delays. This classification serves to account for delays which the men require, or those to which they are entitled. 
FINDINGS OF STUDY

\section{Methods of Analysis}

The methods of analysis were those discussed in the preceding section, Work Study Analysis. Each film was first reviewed while the analyst familiarized himself with the tasks involved in the completion of the work. The basic construction operations consisted of placing formwork, placing reinforcing steel, and pouring concrete. For each of these three operations, applicable work elements were chosen from the work element classifications. A detailed study was then performed to determine the percentages of the total work time which were represented by each of these work elements. The graphical methods discussed earlier were used to tabulate and compute these percentages. Elements of work which were identified for each operation, and the results of their analysis, are discussed below.

\section{Placing Formwork}

For the analysis of formwork, a basic set of work elements was defined for all samples. These were work of trade, walking without load, walking with load, and delay (includes nonproductive work items $7,8,10$, and 11 described on page 28). Work of trade and walking with load were considered as productive work elements while walking without load and delay were considered nonproductive. This classification of the walking activities is admittedly a debatable one. The objective is 
to distinguish between productive and nonproductive times, and it is reasonable to assume that any walking done by a tradesman must be somewhat nonproductive. At the same time, to the extent that walking contributes to the progress of the job, it can also be classed as productive. Since quantitative results were needed, it was assuned that one-half of the total walking time was nonproductive. Since the percentages of the two walking activities were nearly equal in all cases, placing one in each category allotted approximately one-half the total walking time as nonproductive.

The classifications or elements used here are "gross" elements of work. A thorough analysis would involve a detailed study of each element. A detailed breakdown and follow-up of walking would consider where the man is walking, where he came from, why is he walking there, and if it is necessary at all.

\section{Record of Results}

The analyses of samples from five job sites, involving the work of three contractors, are summarized in Table 2. These figures are based on 348 man-hours of work by carpenters. They indicate that the carpenters spent from 25 to 53 percent of their working day engaged in nonproductive activities. A portion of the nonproductive category is classed as delays or idle time. The items classed as idle are: waiting for materials, tools, and equipment, held up by other tradesmen, idle for no reason, and personal delays. This classification indicates that the carpenters spent from 18 to 42 percent of their time doing nothing constituting a work activity. 
Table 2. Summary of Percentages of Time Spent on Various Activities by Carpenters

\begin{tabular}{|l|c|c|c|}
\hline \multirow{2}{*}{ CLASSIFICATION } & \multicolumn{3}{|c|}{ CONTRACTOR } \\
\cline { 2 - 4 } & A & B & C \\
\cline { 2 - 4 } & $\%$ & $\%$ & $\%$ \\
\hline Work of Trade & 35 & 51 & 68 \\
Walking with Load & 12 & 3 & 7 \\
Walking without & & & 7 \\
Load & 11 & 42 & 18 \\
Delay & 42 & & \\
& & & \\
\hline
\end{tabular}

\begin{tabular}{|c|c|c|c|c|c|c|}
\hline \multirow{3}{*}{ CLASSIFICATION } & \multicolumn{3}{|c|}{ PRODUCTIVE } & \multicolumn{3}{|c|}{ NON-PRODUCTIVE } \\
\hline & A & $\mathrm{B}$ & c & A & $\mathrm{e}$ & c \\
\hline & \multicolumn{6}{|c|}{ PERCENT OF TOTAL TIME } \\
\hline Work of Trade & 35 & 51 & 68 & & & \\
\hline Walking with Load & 12 & 3 & 7 & & & \\
\hline $\begin{array}{l}\text { Walking without } \\
\text { Load }\end{array}$ & & & & 11 & 4 & 7 \\
\hline \multirow[t]{2}{*}{ Delay } & & & & 42 & 42 & 18 \\
\hline & 47 & 54 & 75 & 53 & 46 & 25 \\
\hline & & & & & & \\
\hline
\end{tabular}




\section{Placing Reinforcing Steel}

As in the case of formwork, the four basic elements of work of trade, walking with load, walking without load, and delay were chosen to report the data found for ironworkers placing reinforcing steel. The activities work of trade and walking with load were considered productive, those of walking without load and delay, nonproductive.

\section{Record of Resuits}

The analyses of samples from six job sites involving the work of three different contractors are summarized in Table 3. These are based on 325 man-hours of work by ironworkers. They indicate that the ironworkers spent from 28 to 48 percent of their working day engaged in nonproductive activities. The results of delays or idle time indicate that the ironworkers spent from 10 to 36 percent of their time doing nothing constituting a work activity.

\section{Pourine Concrete}

A different set of work elements was present in the concrete pouring operation, and the breakdown of activities was therefore modified.

The work force included two machines, a conveyor belt material distributor and a finishing or strike-off machine, whose time could be classified either as productive or nonproductive. The work force also included two men who operated portable vibrators. Because vibration was the only work they did, their time was also either productive or nonproductive. 
Table 3. Summary of Percentages of Time Spent on Various Activities by Ironworkers

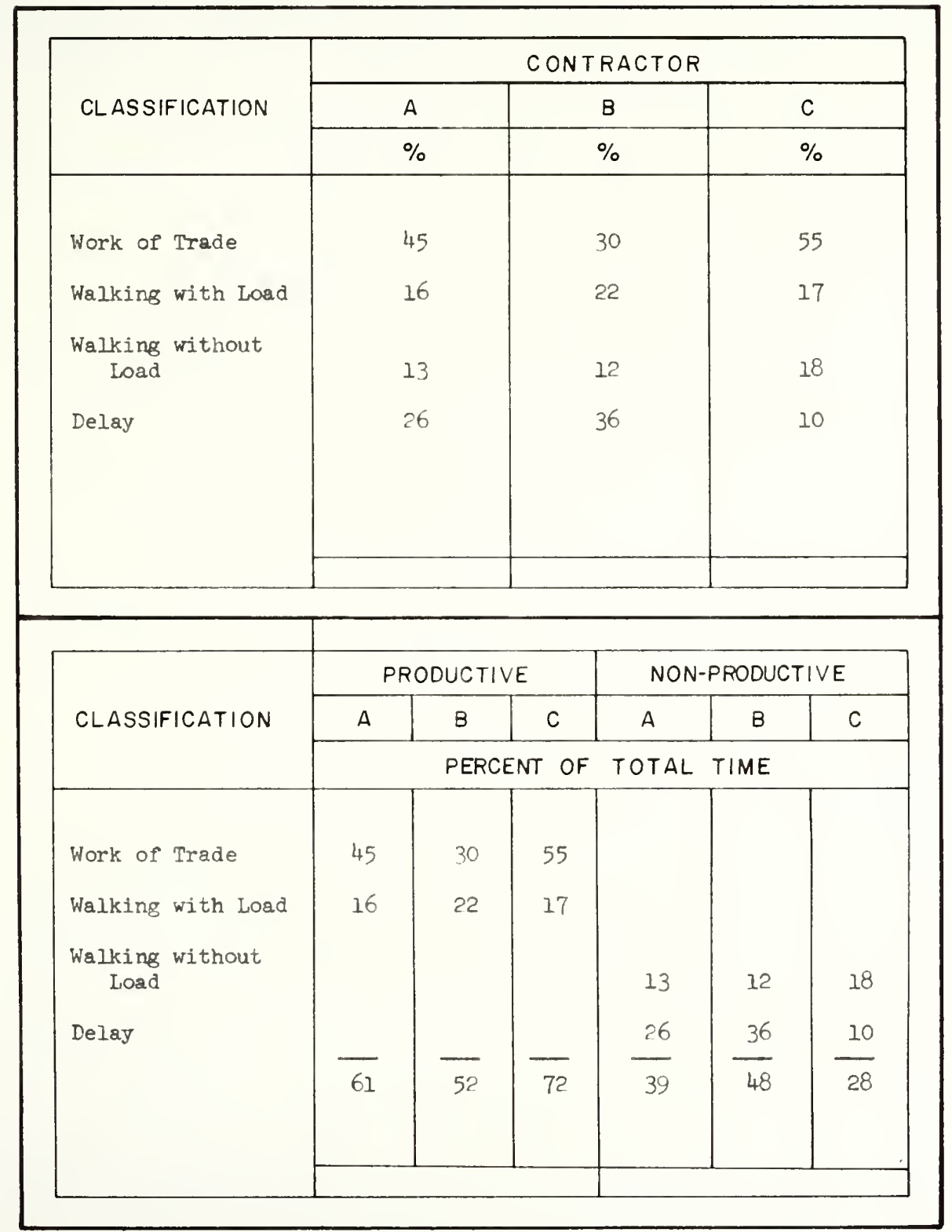


Record of Results

The results of 522 man-hours of work by the laborers are summarized in Table 4. These indicate that the laborers spent from 59 to 65 percent of their work day doing nothing constituting a work activity.

The results of 260 machine-hours of work for each type of machine are sumarized in Table 5.

\section{Selected Examples of Complete Analys is of Work}

The analytical phase of a work study must, of course, go further than determining the percentage breakdoms of various work elements for machines and workers. To be effective, the study must then proceed to reduce the percentages of nonproductive time.

The analysis of selected work samples, as obtained in this study, will be described in the following paragraphs. Each example is deliberately chosen to illustrate a different study approach to the four areas of work simplification.

\section{Formork}

In the first example, the analysis led to a method improvement and to a rearrangement of worker interrelationships. The crew included three carpenters and one laborer. and the work consisted of placing prefabricated framing sections as a part of the construction of deck forms. The sections were held in place by struts wedged against the bottom flange of the beams, as shown in Figure 7 .

Each section usually required minor modifications prior to placement in order to clear obstructions such as cover plates, bolt heads or diaphragms. Two carpenters generally worked together on the modification 
Table 4. Productive and Idle Time for Laborers Vibrating Concrete on Bridge Decks

\begin{tabular}{|c|c|c|c|c|c|c|c|c|}
\hline \multirow{2}{*}{ CLASSIFICATION } & \multicolumn{4}{|c|}{$\%$ PRODUCTIVE } & \multicolumn{4}{|c|}{$\%$ NON-PRODUCTIVE } \\
\hline & \multicolumn{4}{|c|}{ CONTRACTOR } & \multicolumn{4}{|c|}{ CONTRACTOR } \\
\hline & A & B & C & D & A & $B$ & C & D \\
\hline VIBRATING & 35 & 35 & 41 & 35 & & & & \\
\hline IDLE & & & & & 6 & 65 & 59 & 65 \\
\hline
\end{tabular}


Table 5. Productive and Idle Time for Machines Used in Concrete Pouring Operations

\begin{tabular}{|c|c|c|c||c|c|c|}
\hline \multirow{2}{*}{ MACHINE TYPE } & \multicolumn{3}{|c||}{ PRODUCTIVE } & \multicolumn{3}{|c|}{ IDLE } \\
\cline { 2 - 7 } & \multicolumn{2}{|c|}{ CONTRACTOR } & \multicolumn{3}{|c|}{ CONTRACTOR } \\
\hline \multirow{3}{*}{ DISTRIBUTION } & A & B & D & A & B & D \\
\cline { 2 - 7 } & & & 60 & 77 & & 40 \\
FINISHER & 69 & 53 & 73 & 32 & 47 & 27 \\
\hline
\end{tabular}

Note: Contractors $A$ and $D$ used different distribution systems; Contractor $B$ used none. 


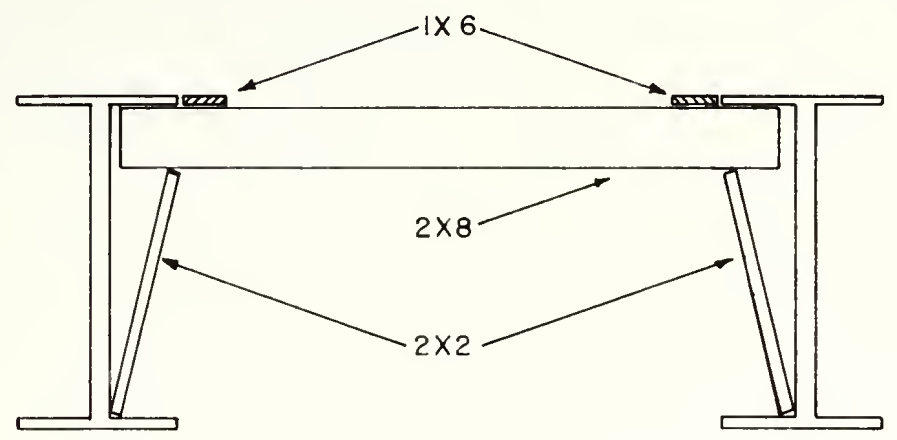

SECTION

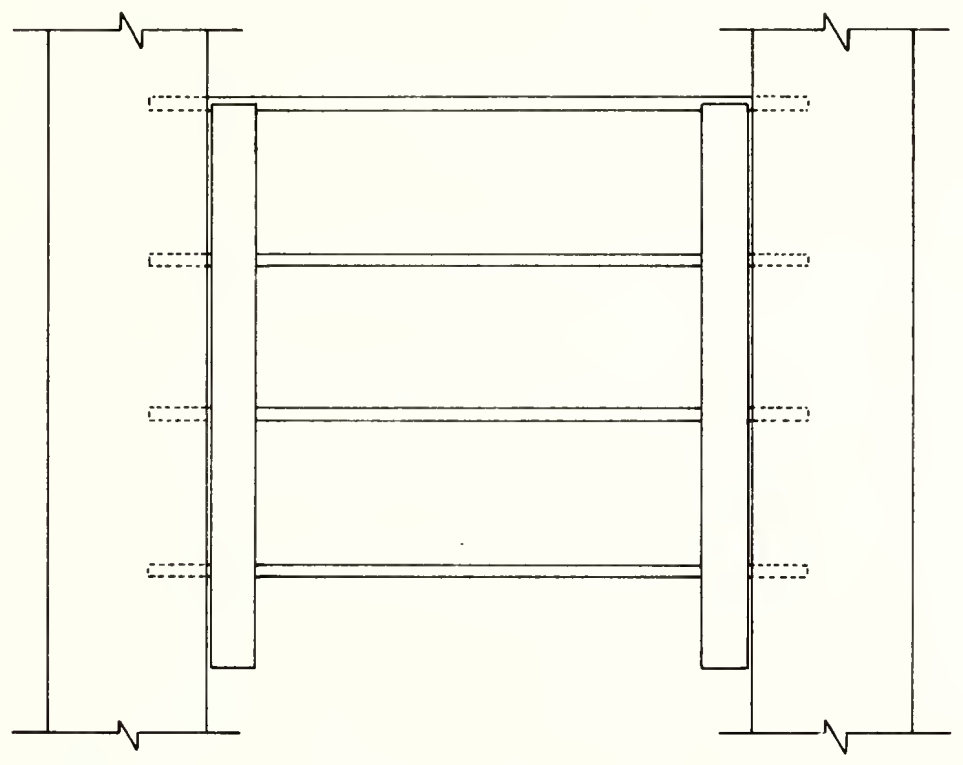

PLAN

Figure 7. Deck Form Plans 
operation. Meanwile, the third carpenter and the laborer either did nothing or carried the required materials from the stockpile. When the section was ready for placement the four men moved it into the final position. The laborer and one carpenter then held it while the remaining workmen placed enough struts to temporarily secure it. With this accomplished the two men finished installing the struts while the carpenter and laborer placed plywood sheeting on the section preceding the one just placed. This work cycle was followed in a general way, with the workers frequently alternating assignments.

A portion of the original process chart for the sequence is shown in Figure 8. The actual time spent on each task varied from cycle to cycle, primarily because of the failure by the crew to utilize a consistent plan of attack. A potential work cycle existed, but was not exploited by the crew. This type of situation will arise often if the work has not been preplanned.

Since a vell-defined work cycle was not present, it was necessary to construct its theoretical equivalent. The observed working times for each operation were averaged over all cycles, and a crew balance chart was then constructed from these average times. This chart is shown in Figure 9, and as nearly as possible, depicts the actual interrelationships between the workers. Because of the relative timing of each task, the crew members wasted a substantial amount of time waiting for coworkers.

The next step in the analysis process was to reconstruct the work cycle so that less time would be wasted and the rate of installation thereby increased. One possibility was to organize the workers so that 


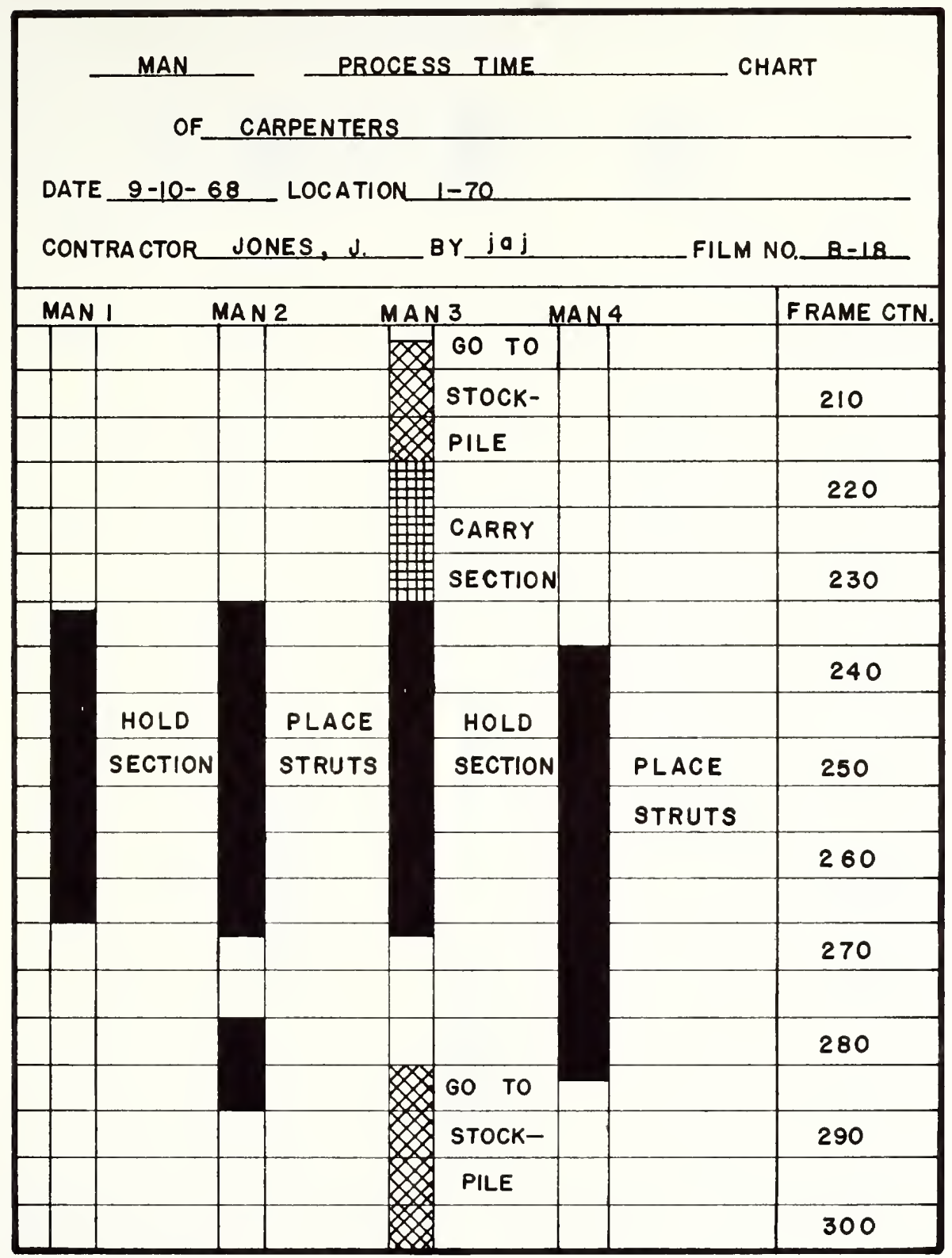

Figure 8. Man Process Time Chart for Carpenters 


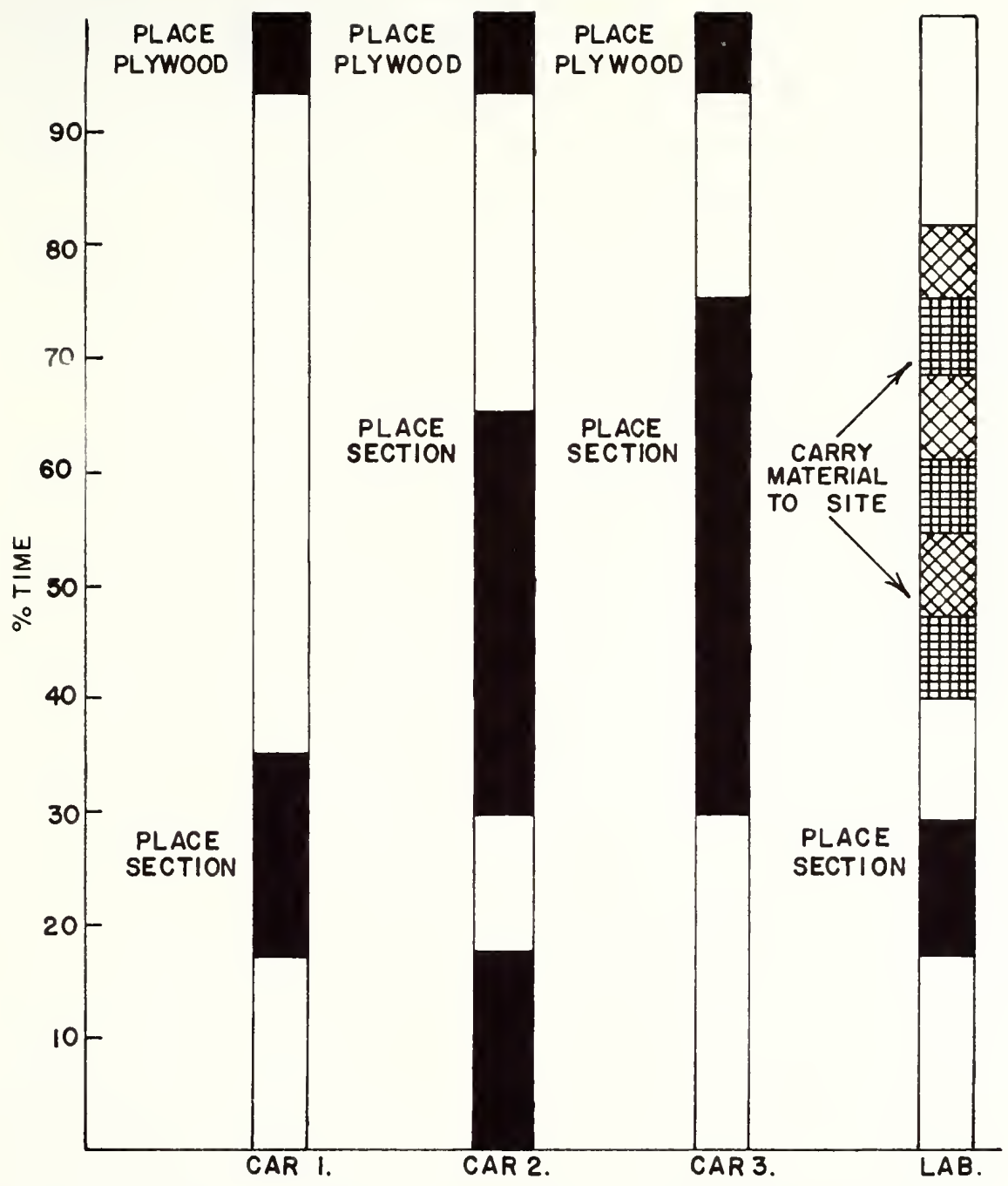

Figure 9. Crew Balance Chart for Carpenters Using Original Method 
the different tasks could be performed simultaneously, and this required an estimate of the number of man-hours required to do each of the tasks. It was assumed that these man-hours were not functions of crew size; that is, if four men must work six minutes to complete a task, then two men can perform the same task in 12 minutes. There are obvious Iimitations to this assumption, since the task may be physically impossible with fewer men. Additional movements within the area where the task is performed may further decrease the efficiency of the fewer men.

In the method actually used, four men were required to position each prefabricated unit. Two of these men served only to hold the unit in place. If a simple hanger were used to support the free end of the unit while it was being nailed to the preceding one, two men could then position and secure the units. While these two men worked, the third carpenter would be free to place plywood on preceding sections and make any necessary modifications on succeeding sections. The laborer would concurrently supply material (prefabricated sections, struts, plywood) to the site.

A crew balance chart for the revised method is shown in Figure 10. The minimum time allotted to each task is based on the productive time requircd by the old method. The limiting task within the proposed cycle is the time in which the laborer can make three trips (prefabricated section, struts, plywood) to the stockpile. The actual time required by the laborer to make the three trips is 55 percent of the old work cycle. This does not allow for rest time for the laborer. 


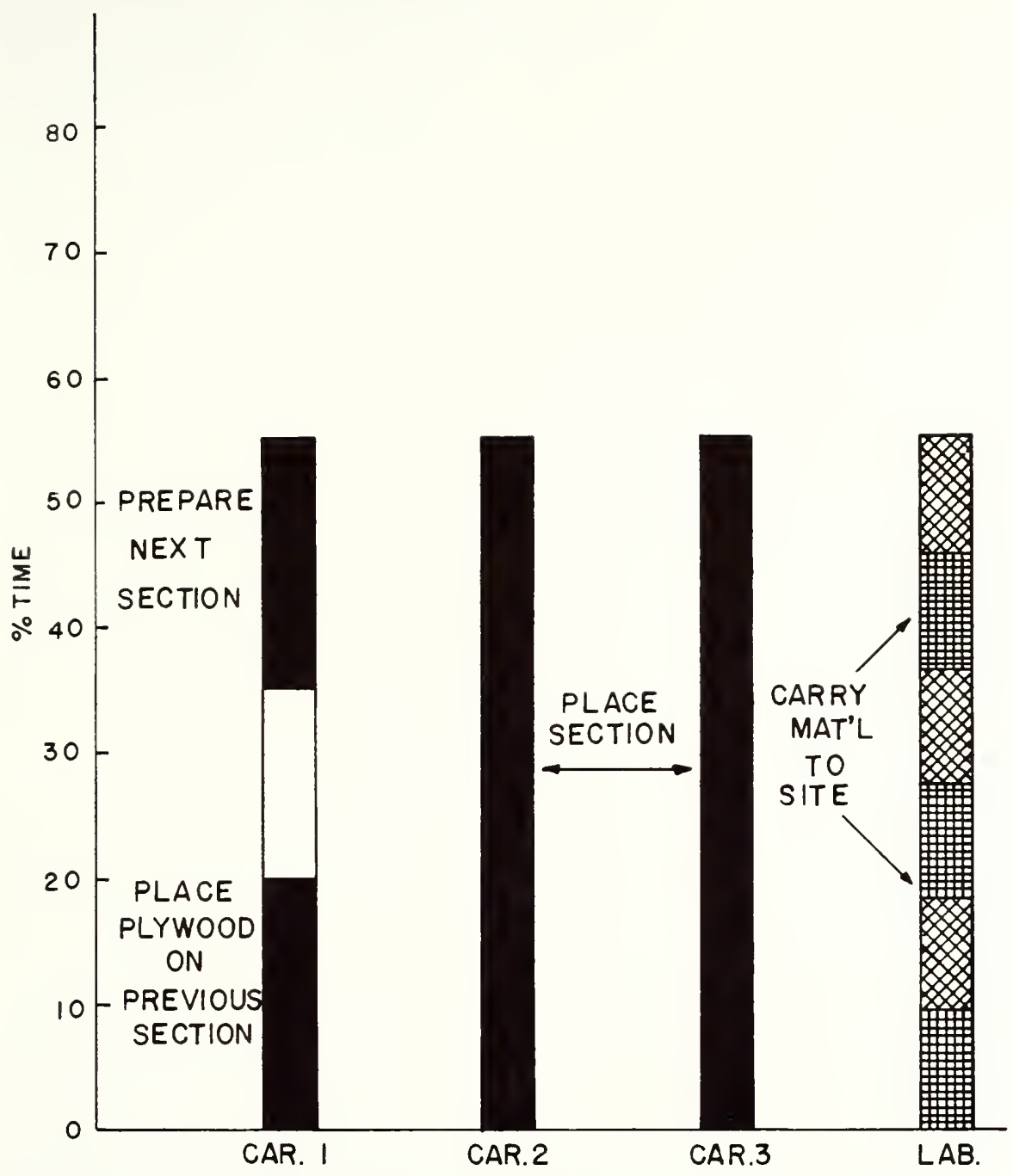

Figure 10. Crew Balance Chart for Carpenters Using Revised Method 
Good utilization of labor does not mean that a man should work every minute. Studies by Frederick Taylor and others have indicated that men engaged in heavy manual labor, such as a stevedore, work most productively with a rest period of 45 percent of total time. (11) For those engaged in medium heavy work the best results are produced if a worker rests $10-15 \%$ of the time (such as ten minutes per hour). (11) Allowances for rest for those engaged in moderate and heavy muscular work cannot be deleted without decreasing production.

With a provision for a 15 percent rest period the new work cycle is 64 percent of the old cycle. With the limitation of the carrying cycle, the time available for other tasks is slightly greater than needed. This is desirable, because placement time may increase with the two man crew and modification time may vary sharply from section to section.

\section{Pouring Concrete}

The second example led to an investigation into the balance of the work forces. The operation was one of pouring concrete on a bridge deck. The machinery system consisted of a Bidwell strike-off or finishing machine, a conveyor for distribution of the concrete on the deck $\bullet$ and a crane to lift the concrete to the conveyor. Plant-mixed concrete was carried to the site in transit-mix trucks. The crane used two buckets so that one could be filled while the other was lifted to the conveyor. As the concrete was placed in the forms, two laborers atilized hand carried vibrators to consolidate it. The analysis included the arrival and unloading of the concrete, its distribution and vibration, and the leveling and floating operations. The hand finishing and brushing operations were omitted from the study. 
The first step in the analysis was to determine the actual production rate for the system by noting the number of trucks which were unloaded, the capacity of each, and the total elapsed time. The system was found to have an average production rate of 38.8 cubic yards of concrete per hour. While making this determination, it was noted that the entire work force was spending a large amount of time waiting for material. A tabulation of delays indicated that concrete delivery trucks were unavailable during approximately 17 percent of the working period. This surmary of delays excluded the time required for one truck to clear the unloading area and another to move into position.

The assumption was then made that peak capacity for the existing system would occur when all idle time had been eliminated from the most critical operation. It was further assumed that the system could operate continuously at the rates implied by actual production and actual productive time. Applying these concepts to the delivery operation, it appeared that the system production could be increased from 38.8 cubic yards per hour to 46.8 cubic yards per hour simply by eliminating the time spent waiting for trucks. However, before making any effort to eliminate this delay, it was necessary to test the rest of the system to determine the effects of an increased flow of material. An increased rate of delivery would be useless if the other components of the system did not have sufficient reserve capacity.

The theoretical peak capacities of the finisher, distribution conveyor, and laborers were accordingly estimated, using the same assumptions as for the delivery operation. From these peak capacities a practical capacity or output must be estimated. For the laborers, a 
a rest period of 10 percent (90 percent productivity) was considered necessary. It was assumed that machinery could be expected to be $35 \%$ productive with routine delays. Major delays such as breakdowns were not considered.

The Bidwell strike off machine was found to have a productive time of 80.6 percent, indicating a theoretical peak capacity of 48.2 cubic yards per hour and a practical capacity of 45.7 cubic yards per hour. The distribution conveyor had a productive time of 25 percent which indicated a peals capacity of 155.0 cubic yards per hour and a practical capacity of 147.0 cubic yards per hour. The laborers had a productive time of 40 percent; on the assumption that each did an eaual share of the work, the theoretical peak capacity of each man became 48.0 cubic yards per hour. Allowing 10 percent for rest periods, the practical capacity is 43.2 cubic yards per hour for each man. In the original sample the capacity of the crane-bucket system was the limiting factor. Therefore. the theoretical system capacity of 46.8 cubic vards per hour was also the theoretical peak capacity of the crane-bucket system. The practical capacity (95 percent productivity) was 44.5 cubic yards per hour.

Two possible improvements to the system are apparent. The waiting time for material should be eliminated; one laborer might also be eliminated, possibly on a trial basis since the practical production rate is slightly more than the capacity of one man. If material delays are effectively eliminated, further studies would be warranted on the crane-bucket system and the finishing machine as these capacities will then be the limiting factors. 


\section{Placing Reinforcing Steel}

The third analysis supplies an example of inefficient interrelationships between crews. Four iron workers worked in two-man teams to sort, carry, place, and tie reinforcing steel. Both teams carried steel from the stockpile to the proper place on the bridge deck. After they had positioned a section of steel. all four men worked individually to align and tie the steel. A portion of the process time chart is shown in Figure 11 and the crew balance chart is shown in Figure 12.

In the original work sequence, one-half of the idle time for team I occurred while waiting for team II to leave the stockpile. AII four men had a significant percentage of idle time during the period when the group was tying the steel. In the interest of clarity the crew balance chart shows one block of ldle time and one block of productive time, but in the actual operation productive time was broken up by many short periods of idle time. The apparent reason for the many idle periods was the frequent opportunity for conversation not relating to the job.

A possible solution to the problem of crew conflict is the elimination of one crew. If this is to be done, its effect on production must be considered. In the original work sequence, two carry cycles (one for each crew) were present within each work cycle. Figure 13 illustrates that one two-man crew could complete two carry cycles within the original cycle time if they did not tie the steel. An idle time allowance as high as eight percent would be possible without increasing the original cycle time. Since the usual allowance for rest breaks on medium heavy work is 10-15 percent of total time, it would be advisable 


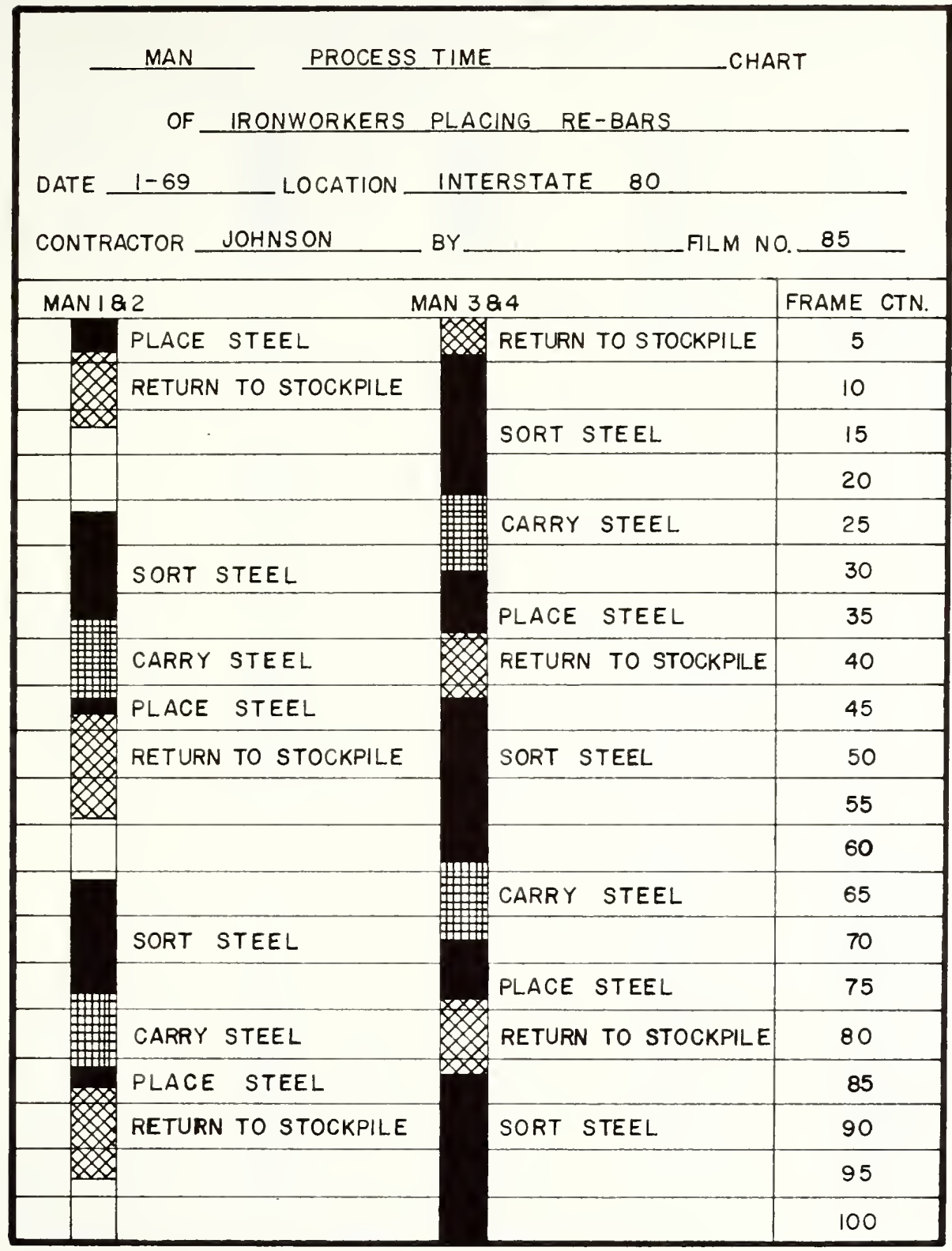

Figure 11. Man Process Time Chart for Ironworkers 


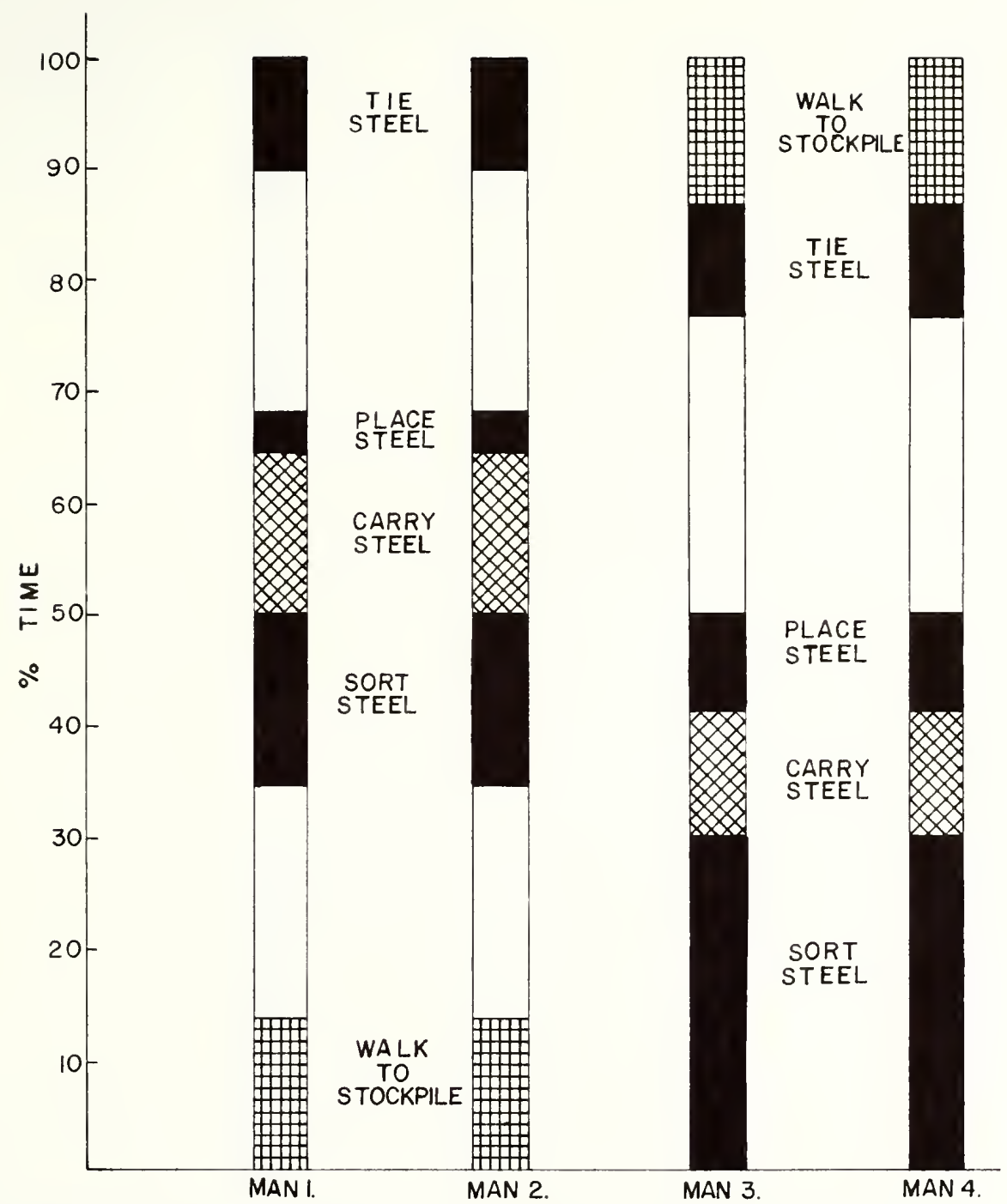

Figure 12. Crew Balance Chart for Ironworkers Using Original Method 


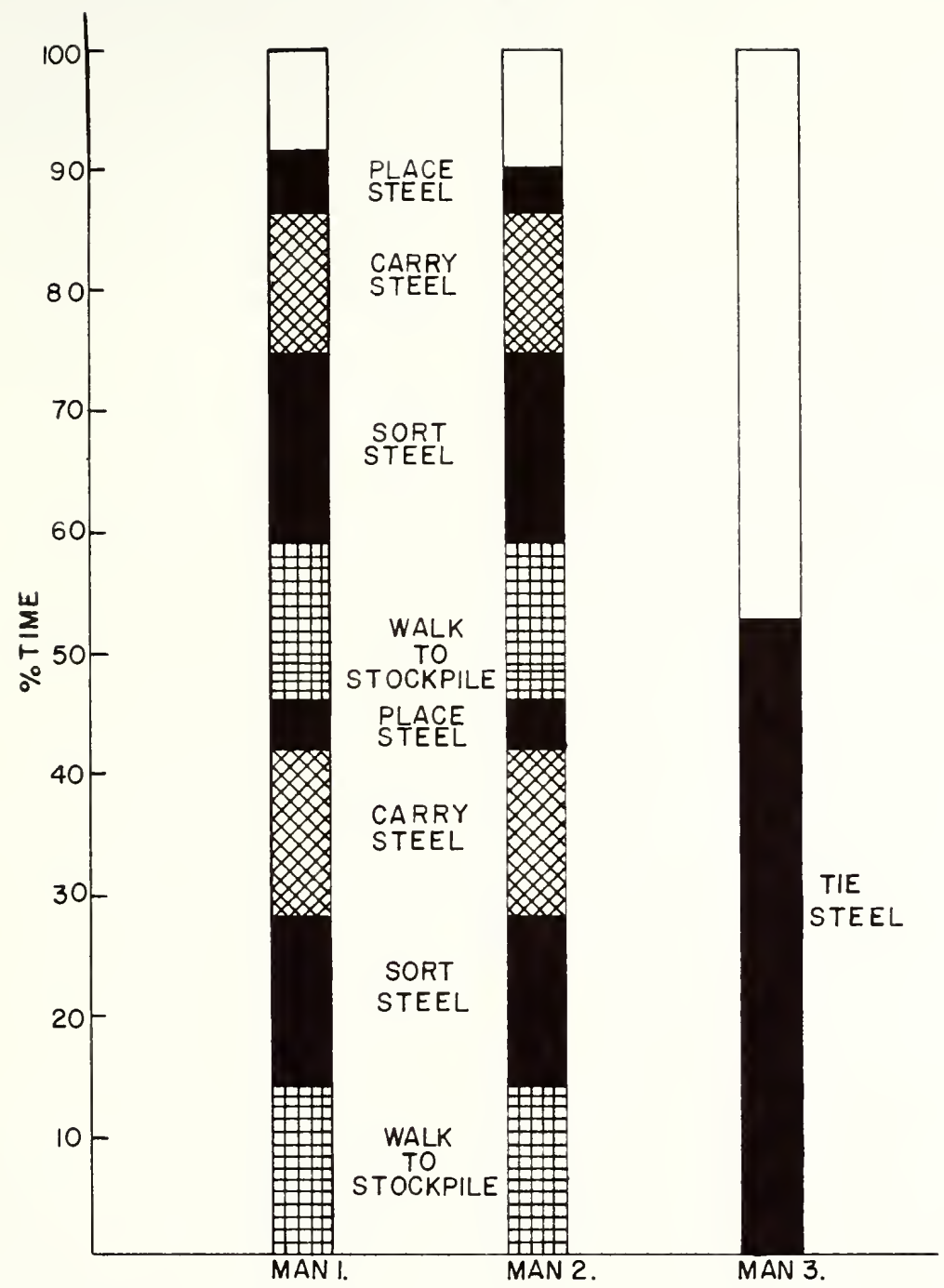

Figure 13. Crew Balance Chart for Ironworkers Using Revised Method 
to allow for a slightly increased cycle time. The significant saving comes from the fact that one man can easily complete the tying operation alone. In the revised crew balance chart it is indicated that 52 percent productive time for one man would be sufficient to keep pace with the carriers. This large percentage of productive time is justified because the waist-bending motion required by the task results in heavy fatigue. The normal allowance for heavy manual labor is 45 percent resting time.

If ten percent resting time is allotted to the other workers, the cycle time is increased slightly more than two percent. This reduction of less than ? percent in output is accompanied by a 23 percent decrease in input. 


\section{CONCLUSIONS AND RECOMMENDATIONS}

\section{Conclusions}

One of the initial objectives of this study was to help highway constructors increase the efficiency of their work and thereby increase or slow rising costs. It was hoped that improvements and suggestions could be formulated that would be of benefit to all contractors. In a direct sense this goal was not obtained, since it was not possible to define improvements which might be used by all contractors.

Varying methods for performing construction work are prevalent, not only between organizations but also within them. Work simplification studies in construction are not primarily intended to formulate methods to be used on every job, since variations prevent this. Rather, the function of methods studies is to provide an analysis which will auickly return information so that improvements can be implemented while still relevent.

One observation did seem to be applicable to all the work which was studied. The majority of idle time seemed to stem not from inefficiencies in the methods but from a lack of preplanning for the work. In far too many cases there was simply no well-defined plan of attack. The repetitive nature of construction work ma preplanning of primary importance and, in an organization where work study is new, it can be expected that the major emphasis will be given to preplanning improvements. When preplanning is once well developed, subsequent analyses can be directed towards methods improvement. 
The results of the study indicate that there are enough inefficiencies in construction to warrant work study, and that timelapse photography is a tool which can make such study feasible. Because the records must be continuous, economy is an important consideration. Time-lapse photography meets this requirement. The original investment in equipment is low $(\$ 1,000-2,000)$ and operating cost is minimal (approximately $\$ 2.00$ per work hour studied). The record obtained is a complete and permanent one that may be used for any level of analysis. It may also be recalled for estimating or instructional purposes.

Construction managers should be encouraged to evaluate work simplification for their organization. Time-lapse photography is the tool which makes the study feasible.

\section{Recommendations}

It is not recommended that further study be done on the basis of defining changes in methods which will benefit the industry as a whole. The need for study is on an individual basis, and efforts should be made to encourage managers to evaluate work simplification for their organizations. In order to help those interested in such investigation. a work study manual (Appendix A) has been attached to this paper. 
BI BLIOGRAPHY 


\section{BIBLIOGRAPHY}

1. Aird, David C., "Manpower Utilization in the Canadian Construction Industry." Technical Paper No. 156. National Research Council of of Canada Division of Building Research. Ottawa, Canada. September. 1963.

2. Barnes, Ralph M., Work Methods Manual. Ist ed.. John Wiley \& Sons. Inc.. New York. 1963 pp. 9-14.

3. Deatherage, George E. Construction Estimating and Job Preplanning: Mcrraw-Hill Book Company, New York. 1965, pp. 1-17.

4. Fondahl. John W. "Photographic Analysis for Construction Operations." Proceedings. Construction Division. American Society of Civil Engineers, Vol. 86. I 360, p. 9.

5. Hauer. Daniel J., Modern Management Applied to Construction. McGrawH1ll Book Company New York. I918. p. 7.

6. Karn. H. W. and Gilmer, B. Von H. Readings in Industrial and Business Psychology. Mctraw-Hill Book Company. New York. I05ई. p. If.

7. Nadler. Gerald. Motion and Time Study, McGraw-Hill Book Company, New York. 1955, pp. 4I-6⿳⺈.

8. Nadler, Gerald, and Irwin. R. D. Work Design. McGraw-Hill Book Company, New York, 1962, p. 7é.

a. Nadler, Gerald, Work Simplification: McGraw-Hill Book Company, New York. 1,57. pp. 75-120.

10. Parker. Herry W.. "Method Improvement Techniques for Construction and Public Works Managers," Technical Report No. 51, Stanford University, Stanford. Calif. Aug., I965.

11. Taylor, Frederick M. . The Principles of Scientific Management. Harper and Brothers, New York, 1911. pp. 4l-47.

12. Turner. G., and EIIiott. K., Profect Planning and Control in the Construction Industry. Cassell and Company Ltd., London, 1964. pp. $115-226$. 
APPENDICES 
APPENDIX A

TIME-LAPSE PHOTOGRAPHY

APPLICATION TO CONSTRUCTION METHOIS STUDIES - A GUIDE MANUAL Equipment for Time-Lapse Fhotography Study

The first step in initiating a time-lapse photography stury is the choice of equipment. It is important that this equipment satisfies the specification requirements which are discussed in the following pages. Since there are many suitable systems, a basic decision must first be made as to equipment type. There will still remain the choice of renting or buying new or used equipment. A partial list os equipment suppliers can be sound in Appendix C.

\section{Time-Lapse Camera}

The main requiroment for the camera is that it be cabable of takinf single frame pictures. The wide variety of suitable cameras and accompanying profection equipmert is divided into tio aroups, In mm and $8 \mathrm{~mm}$, accoraing to film size. Nearly all $8 \mathrm{~mm}$ equipment is now in the Super category. with a slightly lareer picture than the old $8 \mathrm{~m}$. In the past, the $16 \mathrm{~mm}$ format was reserved for the sophisticated semiprofessional equipment while the $8 \mathrm{~mm}$ format was used for lower quality home movie equipment. Recently this trend has changed as the $8 \mathrm{~mm}$ equipment has become more elaborate, and the 8 mon equipment now available is quite suitable for use in a time-lapse photography study. 
A prominent advantage of $8 \mathrm{~mm}$ equipment is its lower cost. Its purchase price and operating costs (film and processing) are approximately one third those of the $16 \mathrm{~mm}$ format. (10) This factor favors the purchase of $8 \mathrm{~mm}$ equipment if new equipment is needed, but does not preclude the use of $16 \mathrm{~mm}$ equipment which an organization already owns.

The actuating mechanism for the camera usually consists of a battery powered solenoid to trip the single frame mechanism of the camera. Many cameras have integrally mounted motors or solenoids for single frame operation. For cameras not so equlpped auxillary solenoids which mourt on the tripod or camera are available. The integral solenoid is a better choice because mechanical devices that are originally designed as a unit are senerally more dependable and less susceptable to maladjustment and damage.

For all types of cameras a wide assortment of lenses is available with viewing fields ranging from wide angle (large field) to telephoto (small field and strong magrification). A selection of lenses is needed so that the field of vision can be quickly selected and adjusted. This capability can be provided by using a camera equipped with a turret lens. which is simply a movable circular plate which mounts several lenses. A more desirable method is to use a zoom lens, since this has an infinitely adjustable focal length within certain boundary limits. A typical model has a focal length range of $17-85 \mathrm{~mm}$. The focus and lens opening are linked to the zoom control so that once the lens is adjusted for exposure and focus it is adjusted for any focal lergth chosen. The zoom Iens en bles the photographer to adjust the size of the viewing area precisely to the situation at hand. This can be done smoothly and easily while the camera is in operation. 
Many newer cameras, especially in the $8 \mathrm{~mm}$ size. feature automatic exposure control. This eliminates the need for a light meter and frequent manual settings of the lens aperture. The camera adjusts automatically as the movement of the sun or occasional clouds change the light level. Such a feature is well worth any extra cost.

Film

For time-lapse photography color film is the most destrable choice. The color reproduction allows the analyst to identify men and other subjects to a much higher degree than with black and white film. For subjects which are raturally lighted in the daytime, Kodachrome II daylight color film will give excellent results. For unusual conditions. films are available which will take satisfactory pictures in virtually any lighting condition.

\section{Timine Mecharism}

The key component of the time-lapse equipment is the timer which contr)ls the interval between frames. Since the reliability of the filmed data for use in analysis depends directly on the accuracy of the timer. the variation in the timing cycle should be within $\pm 1 \%$ ( 10$)$ The timer must be self-powered because sources of power at constriction sites are not normally extensive enough to be depended upon. For filming construction work the timer should be capable of 1.2 , and 3 second intervals. (10)

The available timing systems fall into one of two categories, electronic or mechanical. In the electronic models circuits are fabricated which generate signals, or pulses of electronic current, at 
uniform and adjustable intervals. Solid state circuits can be battery powered and would be entirely suitable except for the fact that performance can sometimes be severely affected by environmental conditions. The problem, especially with the less expensive and sophisticated designs, is sensitivity to temperature and humidity fluctuations. Since accuracy is of mafor importance the reasonably priced electronic timers are usually inadequate.

Most mechanical timers consist of a constant speed motor which drives a cam or linkage system to operate miniature switches. There are complete timers available as well as components suitable for fabrication of equipment. In this project a small 24 volt constant speed motor was used to operate micro-switches. The unit shown in Figure 14 was constructed after two electronic timers were tested and found unsatisfactory. The power for both the 24 volt shutter solenoid and the timer motor was provided by a power pack consisting of four 12 -volt dry cell batteries (two systems of 24 -volts each).

\section{Frame Counter}

A frame counter must be incorporated into the timing mechanism so that the photographer can provide frame number references to any notes made during the filming of the work sequence. A similar counter on the reviewing projector will enable the analyst to recall the notes at the proper time.

Projection Equipment

Of the several types of equipment available for reviewing motion picture films, the least expensive is the cormercial film editor. The 

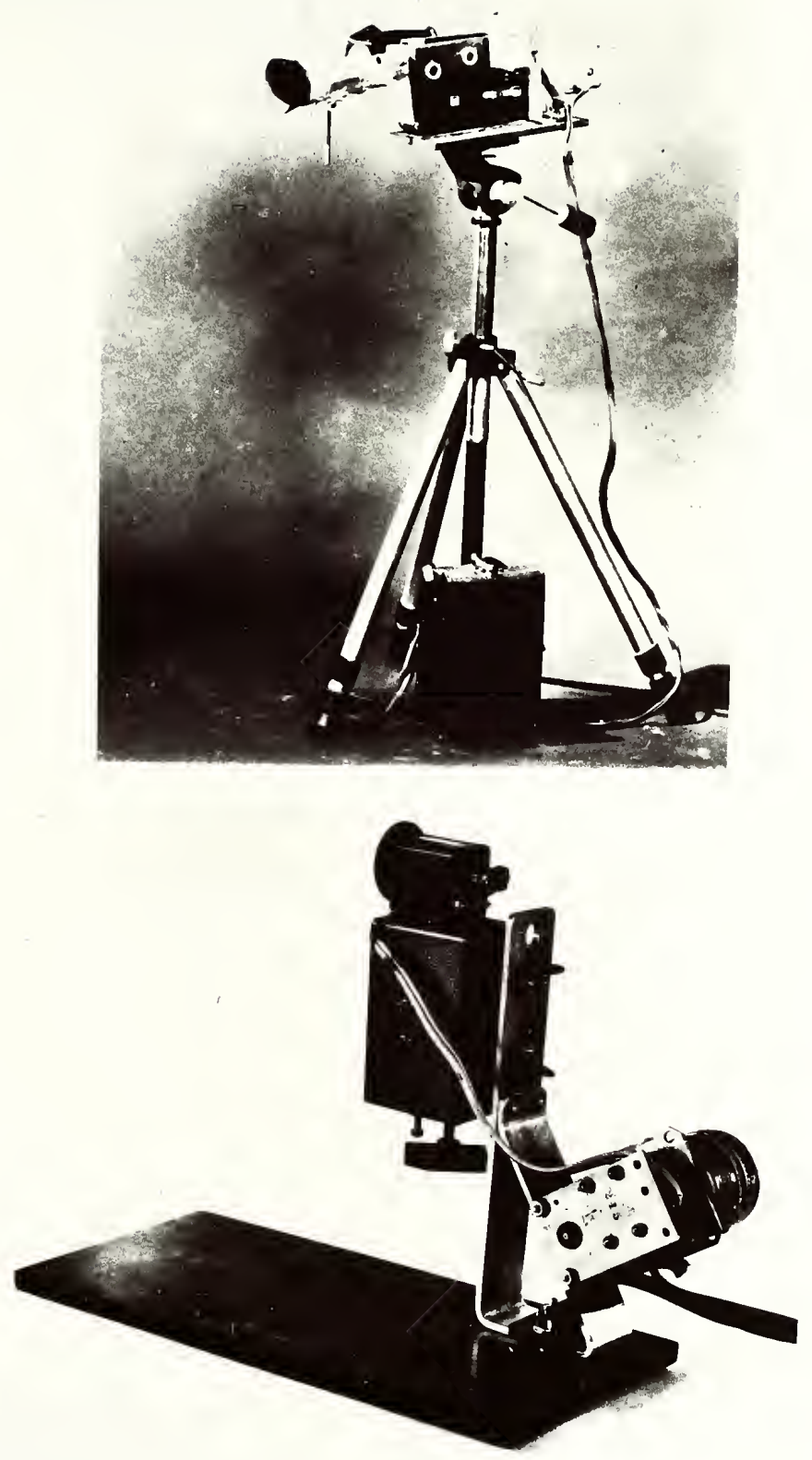

Figure 14. Photographic buuipment 
average model consists of a series of guide wheels, a light source and shutter, and a small. opaque glass screen on which the image appears. Although such a device is very economical it is uswally inadequate for time-lapse study because the small size of the image can hide many important details of the picture. (10)

A second type of reviewing equipment is the hand operated projector. The design is similar to that of the film editor except for a somewhat larger image. The names "film editor" and "hand oderated projector" are many times applied interchangeably to both types of viewer. There is one optional feature that is almost a necessity in this type of equipment. When the eye is viewing a series of pictures in succession, a transition time is requ red as each picture moves ahead to be replaced by the next one. In the less expensive models a shutter covers the lens for a split second as the succeeding picture moves into place in a manner ideritical to that of the camera. The result is a very objectionable flicker at the low speeds used in reviewing (1-it frames per second). The better viewers have a rotating prism which blurs the image from one frame to the next. The light-on, light-off effect is greatly diminished and eye fatigue is much less. (10)

The most expensive and most desirable reviewing equipment is the stop-motion projector. The basic machinery of a stop-motion projector is the same as an ordinary motion picture projector with several additional features. A large capacity blower is used to force a coolings, stream of air over the film so that the projector may be run slowly or stopped without melting the film. The projector is capable of forward and reverse speeds as low as one frame per second as well as manual 
operation on single frames. Several ready-made projectors are available and several companies are marketing modifications of other manufacturers' equipment. As with the hand operated viewers both shutter and prism operated models are available, the latter being by far the best choice. Quality low speed operation is important because it is generally agreed that four frames per second is the maximum allowable speed for efficient reviewing. (10)

Although the stop-motion projector is considerably more expensive than other viewers it is highly recommended that it be used for reviewing. The electric drive is easily controlled in all modes by a remote control unit. The projector has the ability to project pictures large enough so that every detail is reproduced and can be used to present the film sequence to large groups. The advantages of group discussion are substantial and are discussed further in the next section.

\section{Operation of Equipment}

Before attempting to learn the mechanics of operating the camera and related equipment, the photographer should understand the special terminology used in photography and the reasons for the adjustments made to the camera.

To control the amount of light which reaches the film, the lens of the camera employs a circular aperture which is adjustable for varying light intensities. A small opening is used for a high level of light and a larger opening is used for a lower level of light. The aperture size is calibrated on a unitless scale with values designated as f-stops. Increasing $\mathrm{f}$-stop values indicate decreasing aperture size. Each 
succeeding f-stop (in decreasing numerical order) allows one-half as much light to pass through the lens to the film.

The lens aperture required for proper exposure of the film is dependent upon three variables. The amount of light available is the only outside variable. The other variables, film sensitivity (speed) and shutter speed, are characteristic of the equipment used. Film sensitivity is measured by one or both of two unitless scales known as ASA and DIN. The shutter speed is the length of time that the shutter is open so that light may reach the film.

Other than exposure, the lens focus is the only field adjustment to be made. The use of the light meter and the adjustment of the camera for exposure, shutter speed, and focus are discussed in following sections.

\section{Light Meter}

Nearly all light meters have a small calculator built into the case so that the variables of light level. film speed, and shutter speed can be easily correlated to determine the correct aperture size. Figure 15 shows a representation of a typical meter and calculator. Meters and calculators vary somewhat but an understanding of the examples below will enable the photographer to use most models. The first step is the calibration of the meter to the film speed number (ASA or DIN) found on the film package. On the meter shown in Figure 15 the inner circle is moved to set the film speed. The footcande scale on the outer circle is then rotated so that the index mark on the inner circle is at the same location as the needle on the footcandle scale of the meter. The required aperture size ( $f$-stop) can now be read at the 

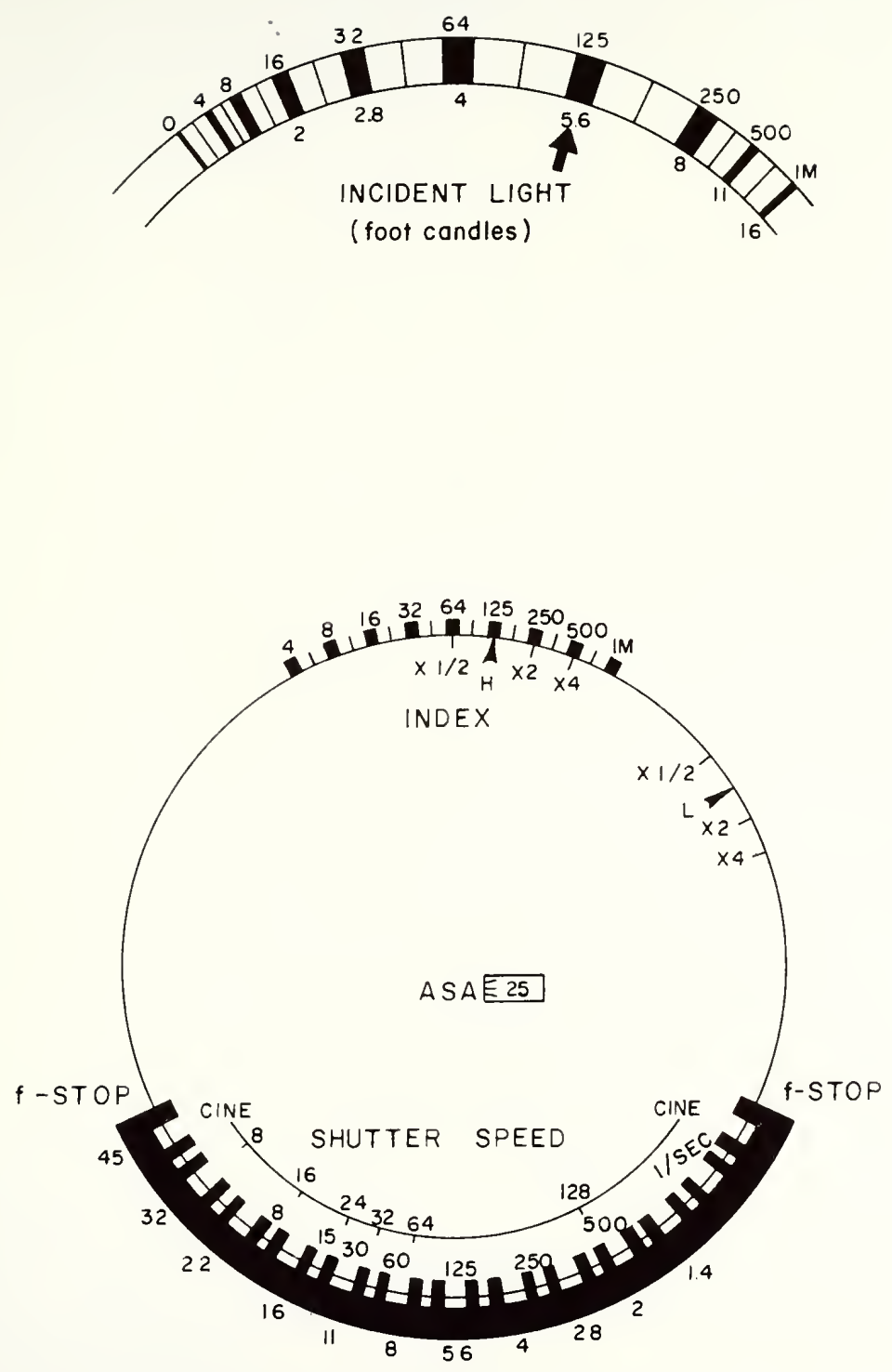

Figure 15. Light Meter 
bottom of the calculator opposite the proper shutter speed. The numbers (iv) shown on the shutter speed scale are actually the denominator of the fraction $1 / \mathbb{N}$ seconds (number 30 equals $1 / 30$ second). The toothed edge on the f-stop scale is provided so that fractions of $f$-stops can be accurately read. In Figure 15 the $f$-stop for $1 / 15$ second is indicated as $f-11+\frac{1}{2}$, and that for $1 / 60$ second $f-8$.

The scale above the standard shutter speed scale is the motion picture scale (CIIVE). This scale merely gives the equivalent shutter speed of the motion picture camera in frames of film per second. In the motion picture camera the film is momentarily held stationary in front of the lens during exposure and the shutter covers the film as each frame moves on and is replaced by the next. If the camera is operating at 24 frames per second the time allowed for a frame to pass the lens is $1 / 24$ second but because the shutter is closed one-half the time the actual exposure time is $1 / 48$ second. The above holds true for normal motion picture operation, but for time-lapse photography a slightly modified assumption is used. Between frames the mechanism of the time-lapse camera is not moving and the inertia of the system must be overcome each time the shutter is released. Because of this, motion during the first frame is somewhat slower, and the assumption is made that the exposure time is doubled. In other words, if the camera is adjusted to run at 24 frames per second in normal operation, the single frame exposure time will be $1 / 24$ second rather than $1 / 48$ second as indicated previously.

On the index mark of the calculator shown in Figure 15 the narkings $\mathrm{X} 2$ and $\mathrm{X} 4$ appear. If the $\mathrm{X} 2$ index (twice the actual amount of Iight) is 
used the f-stop may be read opposite the actual CINE speed for which the camera is adjusted. In Figure 15 the $f$-stop for 24 frames per second is $f-11+1 / 3$.

\section{Camera}

The actual operation of the motion picture camera can be mastered very easily if the photographer will familiarize himself with the mechanics and terminology of the light meter and related information about exposure. The photographer should also practice the various adjustments of the camera and be completely familiar with the controls.

only the focus and the exposure (f-stop) controls on the camera need to be used in the field. On the lens are two rings which rotate about the focal axis of the lens and two corresponding index marks to which the correct f-stop and focus figures are moved. On cameras with automatic exposure control the f-stop adjustment is used only when the automatic control is bypassed. The f-stop scale includes numbers identical to those on the light meter, and the focus scale is marked in feet or meters (from the workplace).

There is nothing complicated about the use of the motion picture camera and if the operator will take the necessary time to familiarize himself with the equipment and work carefully in the field, the settings of the camera will be correct and no film spoilage and lost data will result. 


\section{Hints on Field Technique}

The time-lapse photogrephy operator will learn much from the experience he gains with continued use of the equipment, but during the learning period difficulties are sometimes experienced. The operation of the equipment has been discussed to such an extent that the operator should have no trouble with the equipment itself. There are other nonquantifiable guidelines, which, if followed in a general manner will help the operator to do a better job in the future as well as during the learning period.

\section{Camera Position}

It is very important that the camera be higher than the work place during filming. Only when the camera is higher (at least ten feet) can the relative movements of men and machines be clearly recorded. Extra height helps to eliminate problems with the movements of workers and machinery blocking the line of sight, and it is not necessary to depend on depth perception to see movements along the viewing axis of the camera. Where surrounding structures and topography do not offer a vantage point, a height of ten feet can easily be obtained from a simple platform attop a passenger car. As illustrated in Figure 16, the simplest construction with $2 \times 8$ lumber and smaller is sufficient. The camera tripod itself need not rest on the platform because its weight will not damage the auto. In some cases, such as a paving operation, a more elaborate platform might be desirable because the support vehicle would have to be moved periodically so that the work scene would be within the range of the zoom lens. For such movement the tripod would have to be securely fastened to the platform. 

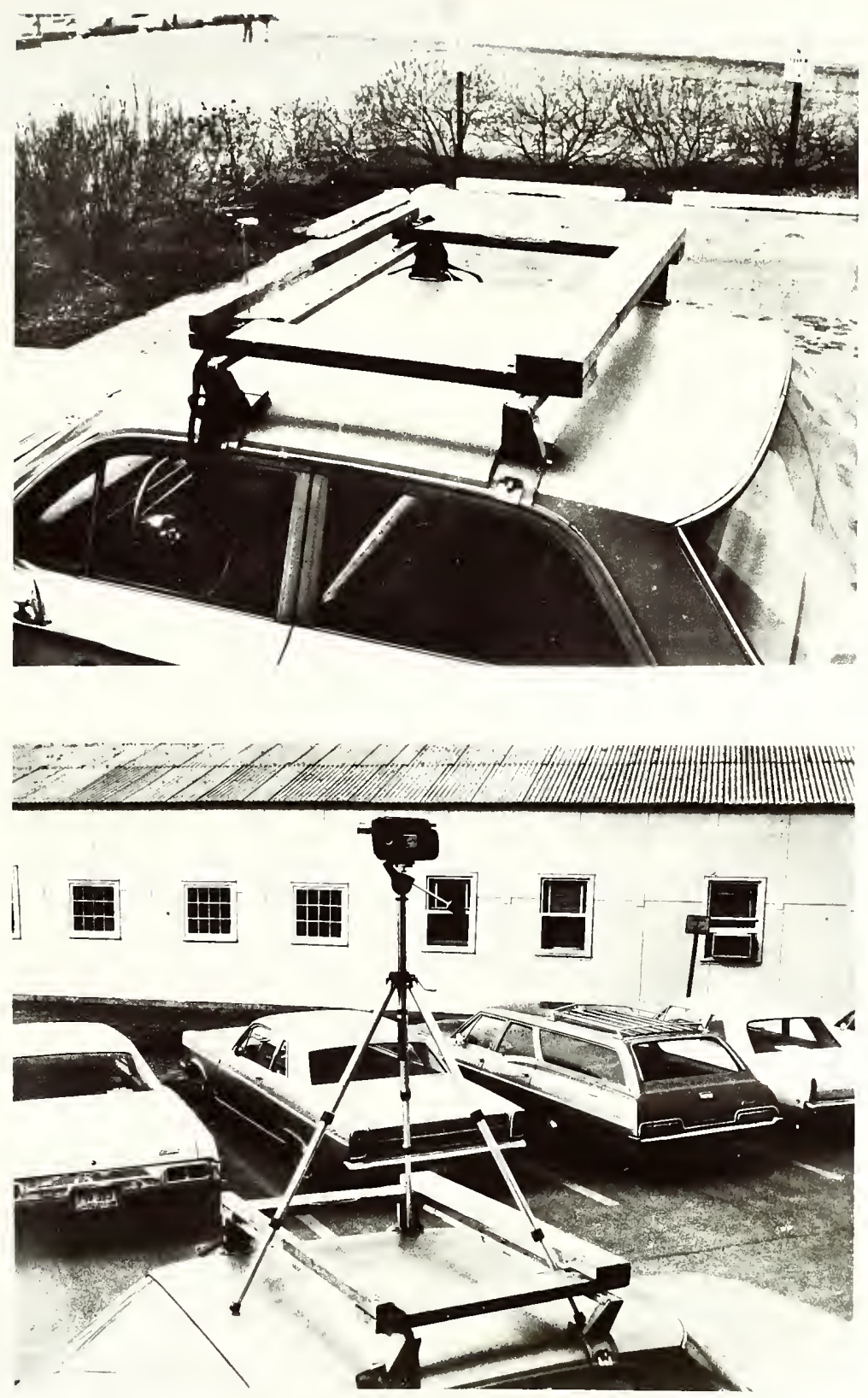

Figure 16. Camera Platform for Autcomobile 
As a supplement to added height, a line of sight perpendicular to the majority of movements of workers and machines will greatly expediate the review of relative movements. This point is especially important when the lens is used in the telephoto mode because the longer lenses radically foreshorten distances along the line of site.

\section{Field of Vision}

The field of vision is the area included in the photograph, and from a given camera position the size of the area depends upon the focal length of the lens. When recording data a large work area will sometimes be encountered and the decision of how much area to cover is a function of the amount of detail desired. If much detail is needed. the larger worksites should be divided into two or more sections and data recorded separately for each. As a guide, if the hand and arm movements of a carpenter crew are to be studied, the minimum size requirements might indicate that the height of a man be approximately one-half that of the picture. If only the body movements are important, the requirement might be a worker height one-fourth that of the picture. When the movements of machines alone are studied, as in a cut-fill operation, the size of the field of vision probably would not be restricted unless some specific detail was desired.

\section{Time Interval}

Closely related to the limitations for size of field are the criteria for the interval between frames. For most studies of construction a speed of one frame every three seconds is satisfactory. (10) The only exception would be a situation where detailed arm and hand 
movements were desired, in which case an interval of one or two frames per second would be suitable. It should be remembered that one of the main advantages of time-lapse photography is the low cost of the film and that the decreased intervals will double or triple the amount of film used.

Recording Supplementary Lata

As already mentioned, one of the advantages of time-lapse photoGraphy is the complete record of all action occuring before the camera. There are still conditions where supplementary notes are needed and desirable. Many times when pertinent action such as the unloading of concrete trucks occurs near the work site, the inclusion of the action in the field of vision would cause an unnecessary loss of detail. In some cases it might be impossible to record the action at all.

Several methods can be used to eliminate this problem. Many times the camera can be turned for one or two frames to include extra information, or a signal card may be held in front of the camera for one frame. A method which utilizes the fillm for recording the extra data is certainly the most desirable, but it will sometimes be impossible to record the information other than by notes. These references can be keyed to the frame count and recalled at the proper location during review by usinf the frame counter on the projector.

\section{Work Simplification Analysis Techniaues}

The basic need for work study is a technique that is based on scientific thinking so that the person who is not, an expert in the field of time and work study can still apply quantitative techniques of improvement to the situation of work at hand. 
The technique of analysis is the most difficult part of work study to quantify and the most difficult skill for the analyst to acauire. It would be convenient if it were possible to formulate a check list which a manager could use for his analysis. However, it is impractical to use a "cut and dried" check list in evaluating the tasks of construction work. The work is not so analytical that it can be defined without making judgment decislons. This does not, however, preclude the use of a plan of attack when initiating a study.

From the definition of work simplification, the objective of a work study is to improve the sequence of work so that it is done with better quality. in less time, at a lower cost and with less effort. The analyst will find that the efforts of work study center around one or more of four areas. Figure 17 shois these areas of work simplification and their interrelationships. Pre-planning is an important area and, unfortunately, is probably the least recognized element of efficient work. Incluted in pre-planning is the pre-instruction of workers and proper scheduling of material, equipment, and labor resources. Many times during analysis it will become apparent to the manager that preplanning was either inadequate or neglected entirely. A certain indication of this is the case of the work task which has an obvious repetitive nature and the work crew which does not utilize a work cycle.

Improvement of technigues is self defining. The guiding philosophy Is that no work method is the best, and a better method can always be found. (2)

Closely related are the balance of work forces and efficiency of interrelationships. The balance of work forces is a measure of the 


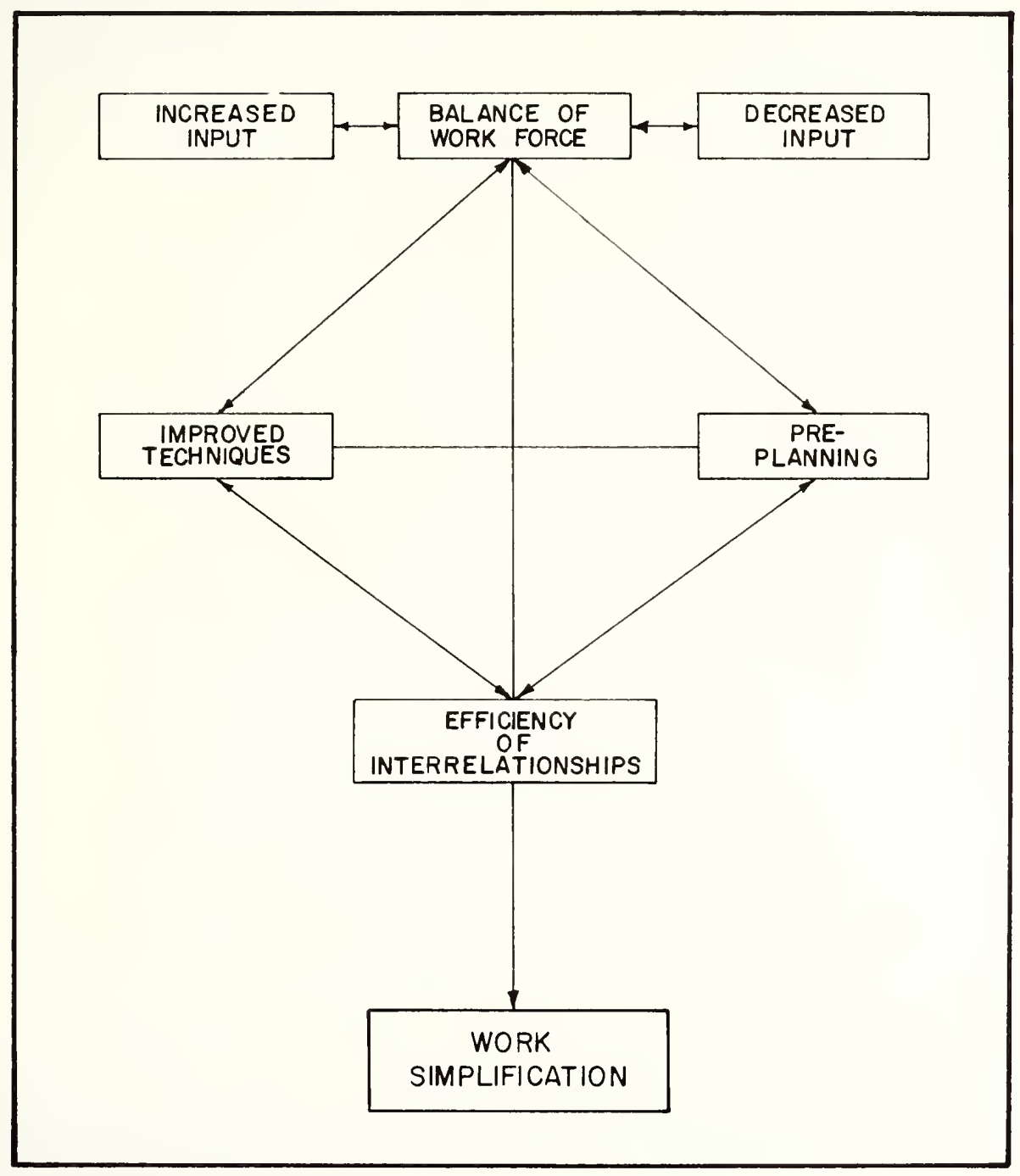

Figure 17. Elements of Work Simplification 
allocations of material, equipment, and labor resources. It is equally bad to have either too many or too few resources and it is important that resource requirements be carefully considered both before and after changes in methods. An evaluation of the efficiency of interrelationships includes the operations of each member of the work force and the interactions and restrictions of these operations. Many times efficiency can be improved simply by a change in sequence which will eliminate conflicting operations.

When work simplification is undertaken, the analyst should be aware of these four possible areas of improvement. The most promising aree or areas can then be identified and studied as the analysis proceeds. During the review of a work sequence. the answers to the questions listed below will be helpful in fully evaluating the worth of each portion of the task.

1. What is the purpose of each item of the task or operation (need it be done at al1)?

2. Where is it done (place)?

3. When is it done (sequence)?

4. Who does it (person)?

5. How is it done (means)?

The use and answering of these questions can help to lead the analjsis of work toward rational simplifications and improvements. (1乞)

\section{Informal Discussion}

The informal discussion of work seauences is probably the most productive technique for analyzing construction work. (10) The timelapse film records lend themselves to group discussion because the 
entire group can view the work scene and discuss the action as if the work were actually occurring before them.

Informal discussion improves the two-way line of commiration between management and labor. Because of the subtle changes in specifications, construction techniques and personnel, management is often several steps behind the conditions in the field. One of the favorite criticisms of suggestions connected with work simplification is "They just don't know what is happening out here." At times this type of criticism is merely a general resistance against an unfamiliar situation, but at other times the accusation is valid becalse management is inadequately informed. Likewise, labor is often uninformed. (10) Tos often during the hurry of the job site instructions to labor are inadequate. Informal discussions can help to bridge these two communication gaps. By including managers, engineers, foreman and even workmen in the planning process the product auality of work study is increased.

The best atmosphere for conducting an informal study is a relaxed comfortable situation away from the hurry of the job site. It is extremely important that all groups feel at ease and unhurried, and it might be necessary to separate the top management group from that of foremen. Only when a group is totally at ease will its members be productive in their thoughts.

The group discussion should begin with a broad review of the work sequence. This step is particularly important when the time-lapse system is new and management is unaccustomed to the fast movement of the film. From the initial review the analysis should be refined, level 
by level, following the most productive path. As the analysis reaches the advanced levels of refinement, the group may divide for further study of work more familiar to the smeller groups or individuals.

The group leader should try to hold the discussion at each level until agreement is reached concerning the problem areas and the path of succeeding analyses. This will not always be possible, but it is important to attempt to obtain agreement so that subsequent arguments will not defeat the purpose of the discussion.

\section{Formal Methods}

Although much productive information can be realized from informal discussion, formal analytical techniques must also be used. A significant amount of time can be saved if the discussion group leader has already chosen portions of the work which will warrant detailed analysis. To enable him to do this, he needs a systematic method of orsanizing the information obtained from his preliminary analysis of the films.

There are many graphical methods of tabulating and analyzing work simplification data. These methods are useful in presenting data and are valuable for use during all subsequent levels of analysis. Two of the more popular methods are discussed in the next section.

\section{Process Chart}

One tabular method for analysis of work is the process chart shown in Figure 18. The man process chart is a symbolic and systenatic presentation of the method of work (series of operations) when movement from workplace to workplace is required. (7) It is an excellent device 
OF Forn Construction

DATE LOCATION

CONTRACTOR BY FILM NO.

DIST. SYMBOL DESCRIPTION TIME (SEC) 50' $\bigcirc$ GO TO STOCKPILE 25

$\bigcirc$ GET PLYWOOD

50' $\ominus$ RETURN TO WORKPLACE

CHECK FIT AND MODIFY

$\bigcirc$ NAIL

$\nabla \quad$ IDLE

50' $O$ GO TO STOCKPILE

$\bigcirc$ GET PLYWOOD

5

50

$\Theta$ RETURN TO WORKPLACE

$\nabla$ PERSONAL BREAK

CHECK FIT AND MODIFY

40

NAIL

50' $\bigcirc$ GO TO STOCKPILE 57

- GET PLYWOOD

$50^{\prime} \theta$

RETURN TO WORKPLACE

10

CHECK FIT AND MODIFY

28

NAIL

15

50

Figure 18. Man Process Chart 
for presentation of pertinent facts gathered about the job. From the analysis of existing conditions, summary charts can be constructed to assist in methods planning and in presenting proposed method changes. The graphic presentation of the chart is an excellent selling feature. Too often suggestions from either management or labor are forgatten merely because the other disagreed initially. If charts are available to illustrate both present and proposed methods, with improvements well annotated, there is a better chance of selling the idea. Facts presented in writing are generally more acceptable than verbally-expressed ideas. (7)

One recommended system of symbols for process charts is shown in Table 6. In addition to the geometric symbols for work operations, a series of time symbols is shown. These symbols are used on a chart which is known as the man process time chart. It differs from the basic process chart only in the fact that the length of each time symbol is proportional to the amount of time over which the activity occurs. Each line of the chart thus represents a definite anount of time. (7) A process time chart for the work illustrated in Figure 13 is compared in Figure 19

Both types of chart are useful for analysis. The basic process chart is more compact and is probably the best choice for simple tabulation and presentation of activity times and percentages. The salient advantage of the process time chart is the ease of tabulating data. The times of each activity are merely taken from the frame counter and marked directly on the chart. The process time chart also gives an excellent representation of the interrelationships of the activities of 
Table 6. Process Chart Symbols

\begin{tabular}{|c|c|c|c|}
\hline $\begin{array}{l}\text { Geometric } \\
\text { Symbol }\end{array}$ & $\begin{array}{c}\text { Time } \\
\text { Symbol }\end{array}$ & Name & Activity Represented \\
\hline & & $\begin{array}{l}\text { Work of the } \\
\text { trade. }\end{array}$ & $\begin{array}{l}\text { Doing something at one work } \\
\text { place. }\end{array}$ \\
\hline & 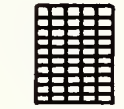 & $\begin{array}{l}\text { Walking without } \\
\text { load. }\end{array}$ & $\begin{array}{l}\text { Change in location without } \\
\text { load (taking more than one } \\
\text { step). }\end{array}$ \\
\hline$\Theta$ & 8 & $\begin{array}{l}\text { Walking with } \\
\text { load. }\end{array}$ & $\begin{array}{l}\text { Change in location with load } \\
\text { (taking more than one step). }\end{array}$ \\
\hline & & Delay (idle). & $\begin{array}{l}\text { Held up by other tradesmen, } \\
\text { waiting for tools and eauip- } \\
\text { ment, idle for no reason. } \\
\text { personal delays. }\end{array}$ \\
\hline & DD & Planning. & $\begin{array}{l}\text { Receiving instructions, } \\
\text { planning, or discussing lay- } \\
\text { out. }\end{array}$ \\
\hline & & Seeking. & $\begin{array}{l}\text { Reaching or searching for } \\
\text { materials, tools, or equip- } \\
\text { ment. }\end{array}$ \\
\hline & & $\begin{array}{l}\text { Work of another } \\
\text { trade. }\end{array}$ & $\begin{array}{l}\text { Work which should be done by } \\
\text { another tradesman. }\end{array}$ \\
\hline
\end{tabular}


CHART

OF

DATE

LOCATION

CONTRACTOR

BY FILM NO.

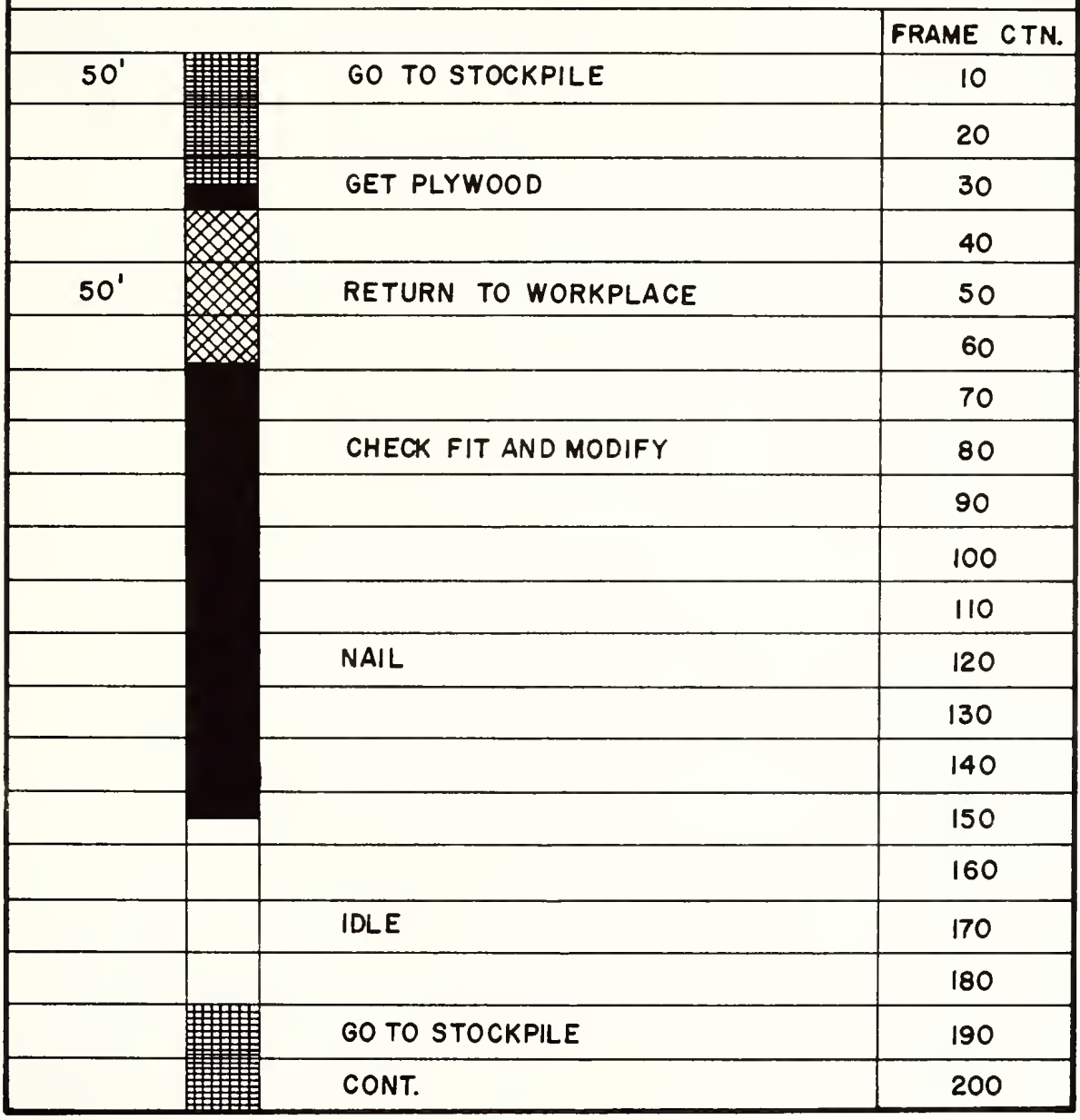

Figure 19. Man Process Time Chart 
men and machines. Since each element of the crew is plotter to the same time scale. interrelationships can be compared along a horizontal line on the chart. (10)

When a single process chart or process time chart presents the activity of more than one man or chine it is often referred to as a multi-activity chart. Other names such as multi-man or man-machine are also used, but are really coined phrases describing what is basically a process chart. A multiple component chart is shown in Figure 20. The figure illustrates how well the interrelationshits among workers are shown.

The process chart is an excellent tool for planning analysis. Since the lengths of all the work cycles are recorded, estimates of time needed to do each task can be established. The planner can then rearrange the cycles of the work force so that the interrelationships among them can be as efficient as possible.

\section{Crew Balance Chart}

A chart very similar to the process chart is the crew balance chart shown in Figure 21. The crew balance chart presents the activities of the work force for one complete work cycle. The crew balance chart and the process chart can be used in conjunction with each other. The process chart can be used to record and analyze, and the crew balance chart can then be used as a work sheet to revise and present the new methods. 


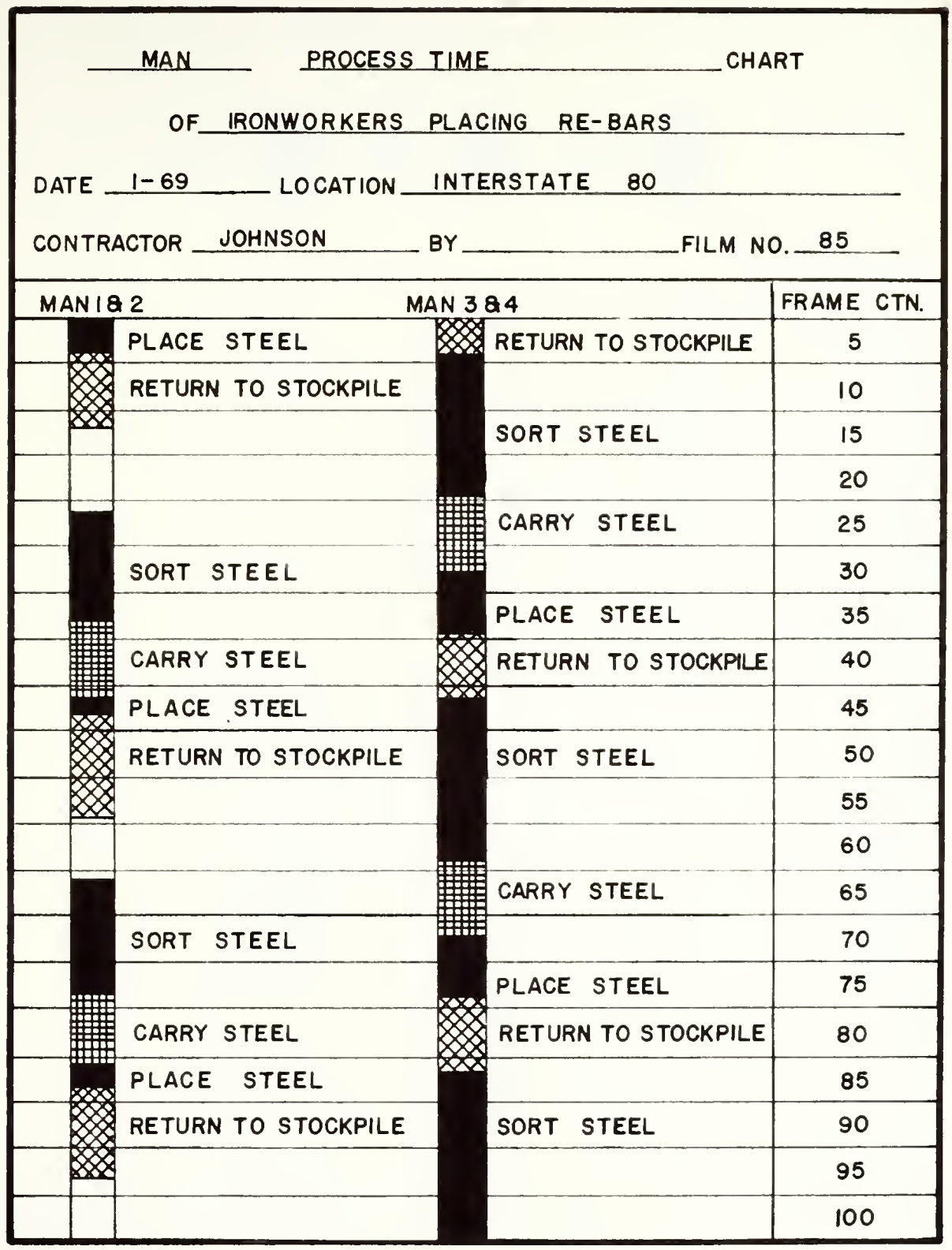

Figure 20. Multi-Activity Chart 


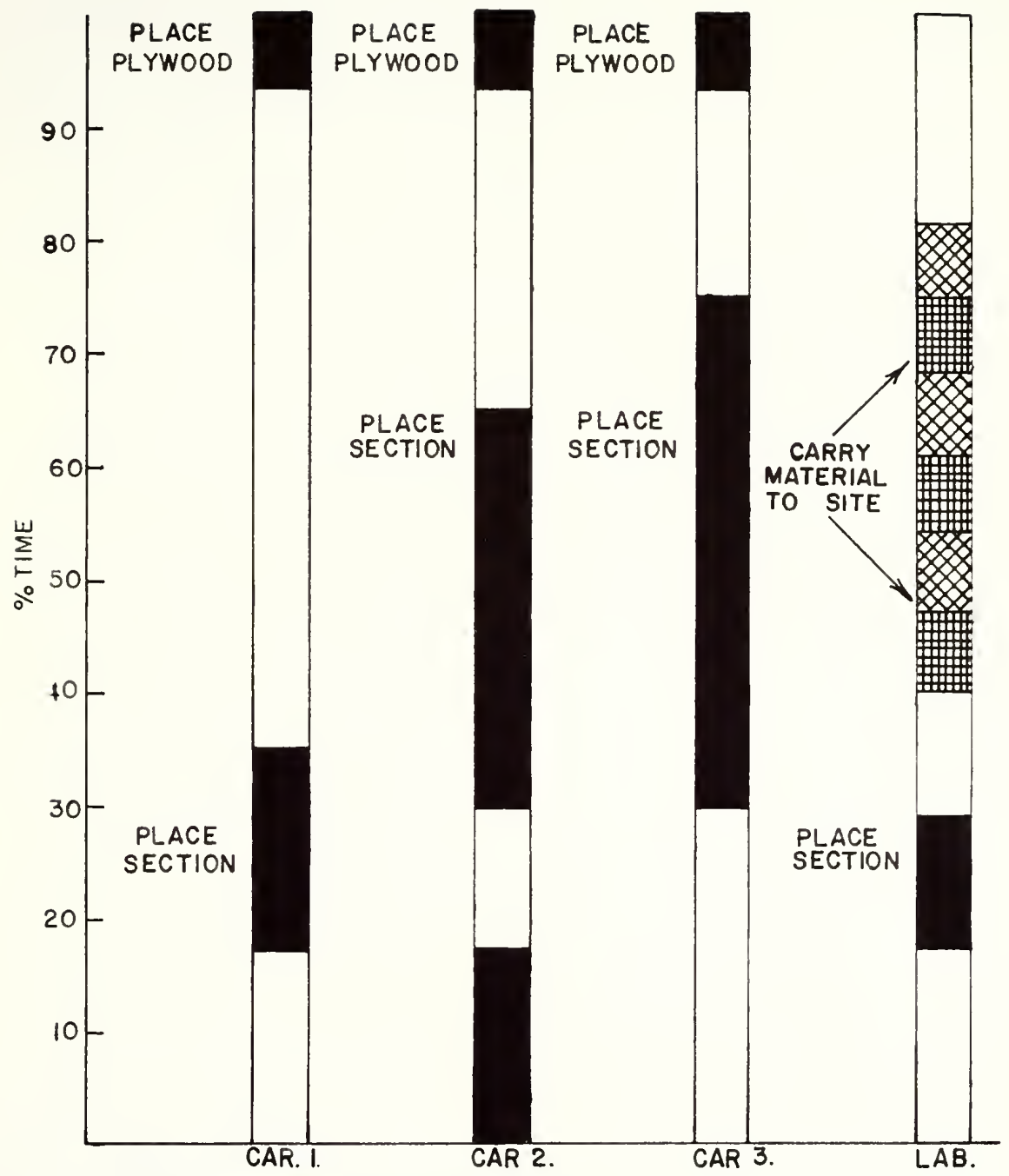

Figure 21. Crew Balance Chart for Carpenters 


\section{Example of Joint Use of Crew Balance Chart and Process Chart}

An example from construction will demonstrate the combined use of the man process chart and the crew balance chart. In the work sequence studied, the crew included three carpenters and one laborer. and the work consisted of placing prefabricated framing sections as a part of the construction of deck forms. The sections were held in place by struts wedged against the bottom flange of the beams, as shown in Figure 22.

Each section usually required minor modifications prior to placing in order to clear obstructions such as cover plates, bolt heads or diaphrams. Two carpenters generally worked together on the modification operation. Meanwhile, the third carpenter and the laborer either did nothing or carried the required materials from the stockpile. When the section was ready for placement, the four men moved it into the final position. The laborer and one carpenter then held it while the remaining workmen placed enough struts to temporarily secure it. With this accomplished the two nen finished installing the struts while the carpenter and laborer placed plynood sheetine on the section preceding the one just placed. This work cycle was followed in a general war. with the workers frequently alternating assignments.

A portion of the original process chart for the sequence is shom in Figure 23. The actual time spent on each task varied from cycle to cycle, primarily because of the failure by the crew to utilize a consistent plan of attack. A potential work cycle existed but was not exploited by the crew. This type of situation wlll arise often if the work has not been preplanned. 


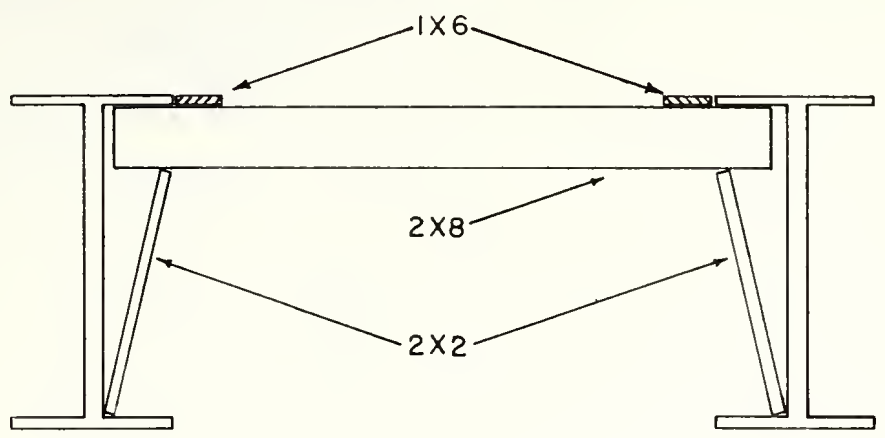

SECTION

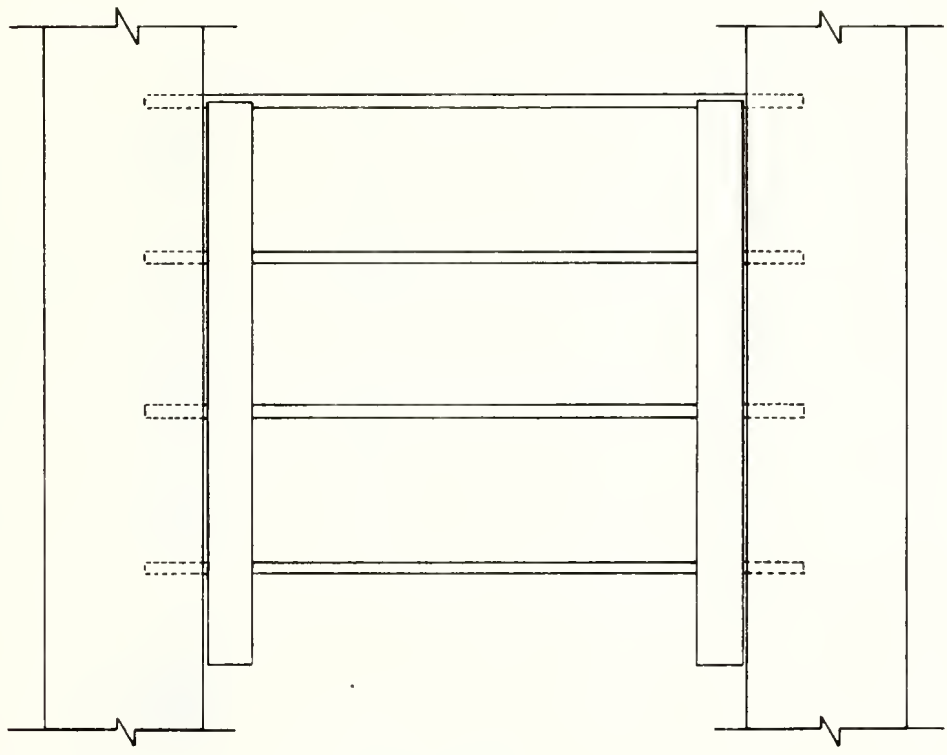

PLAN

Figure 22. Deck Porm Construction 


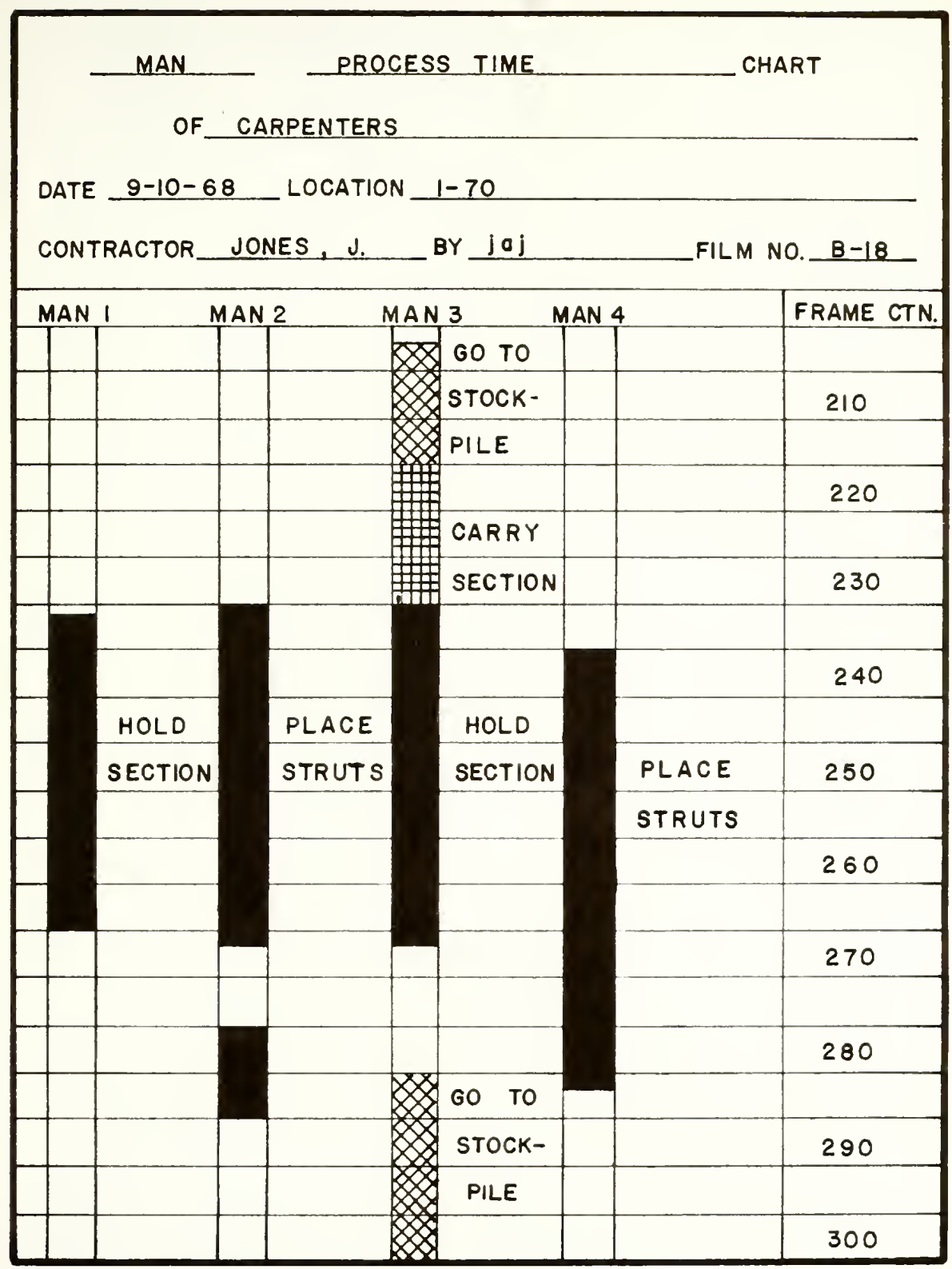

Figure 23. Process Chart for Carpenters 
Since a well-defined work grcle was not present, it was necessary to construct its theoretical equivalent. The observed working times for each operation were averaged over all cycles, and a crew balance chart was then constructed from these average times. This chart is shom in Figure 24 and, as nearly as possible, depicts the actual interrelationships between the workers. Because of the relative timing of each task, the crew members wasted a substantial amount of time walting for coworkers.

The next step in the analysis process was to reconstruct the work cycle so that less time would be wasted and the rate of installation thereby increased. One possibility was to organize the workers so that the different tasks could be performed simultaneously; this reauired an estimate of the number of man-hours recuired to do each of the tasiks. It was assumed that these man-hours were not functions of crew size; that is, if four men must work six minutes to complete a task, then two men can perform the same task in 12 minutes. There are obvious limitations to this assumption, since the task may be physically impossible with fewer men. Additional movemen's within th area where the task is performed may further decrease the efficiency of the fewer men.

In the method actualiy used, four men were required to position each prefabricated unit. Two of these men served only to hold the unit in place. If a simple hanger were used to support the free end of the unit while it was being nailed to the preceding one, two men could then position and secure the units. While these two men worked, the third carpenter would be free to place plywood on preceding sections and make 


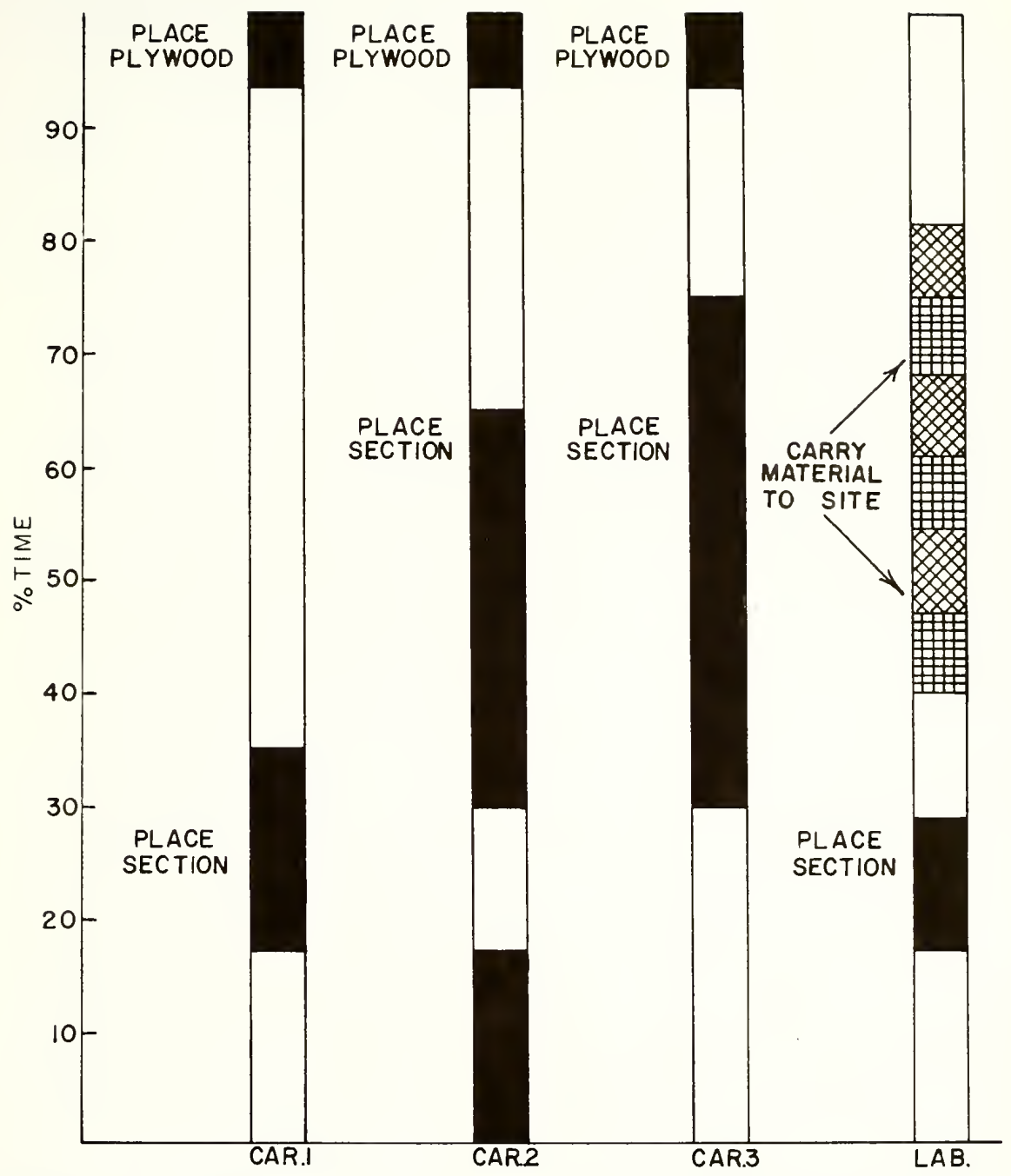

Figure 24. Crew Balance Chart for Carpenters Using Original Method 
any necessary modifications on succeeding sections. The laborer would concurrently supply material (prefabricated sections, struts, plywood) to the site.

A crew balance chart for the revised method is shown in Figure 25. The minimum time allotted to each task is based on the productive time required by the old method. The limiting task within the proposed cycle is the time in which the laborer can make three trips (prefabricated section, struts, plywood) to the stockpile. The actual time required by the laborer to make the three trips is 55 percent of the old work cycle. This does not allow for rest time for the laborer.

Good utilization of labor does not mean that a man should work ever, minute. Studies by Frederick Taylor and others have indicated that men engaged in heavy marual labor: such as a stevedore, work most productively with a rest period of 45 percent of total time. (II) For those engaged in mediun heavy work the best results are produced if a worker rests $10-15$ percent of the time (such as ten minutes per hour). (11) Appropriate allowances for rest for those engaged in moderate and heavy muscular work are necessary if overall production is to be maximized.

Including an allowance for a 15 percent rest period results in a new work cycle which is 64 percent of the actual cycle. With the limitation of the carrying cycle, the time available for other tasks is slightly greater than is needed. This is desirable, because placement time may increase with the two man crew and modification time may vary sharply from section to section. 


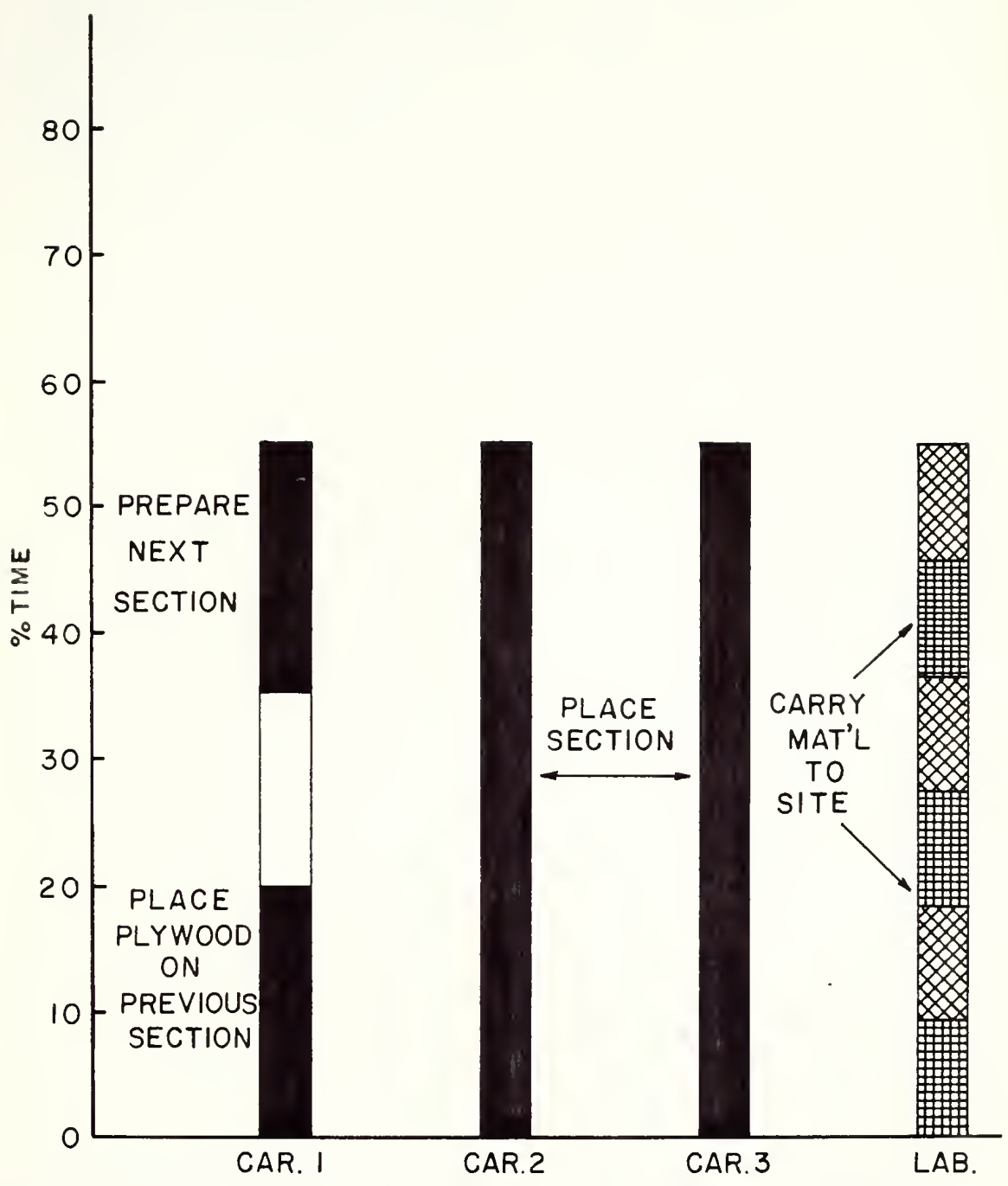

Figure 25. Crew Balance Chart for Carpenters Using Revised Method 


\section{$\underline{\text { Summary }}$}

After the preliminary trial studies, most managers will begin to develop their own methods and techniques. Analysis will become an easier task, and it is important that it continue to be performed with an open mind. The use of group discussion will help to make this possible. Group discussions also help to include more personnel and promote an enthusiasm for the project.

Better methods and more efficient work are available to every company. They are the result of an organized approach to reducine the effort, time, and expense of doing a job. The requisites are a desire to improve, a systematic approach. intelligent skepticism and the ability to improvise. (10)

Time-lapse photography and the related methods of analysis discussed here combine to provide the systematic approach required. A sumarized list of suggested steps to methods improvement using time-lapse photography is shown in Appendix $B$. 


\section{APPENDIX B}

\section{SUGGESTED STEPS TO METHODS IMPROVEMENT}

Record the Job

A. List all details of the job as it is currently performed. Employ crew balance charts, process and flow charts. Include details of hand work, machine work, and materials handling.

I Analyze Every Detail

A. Ask the six basic questions of each detail.

What is its purpose?

Why do it this way?

When is the best time to do it?

Where is the best place to do it?

How is the best way to do it?

Who is the best nualified to do it?

B. Evaluate the job layout, the tools, equioment, materials used material flow, and safety.

III Devise a Better Method

A. With an understanding of the desired objective, develop a better method, by the use of: 


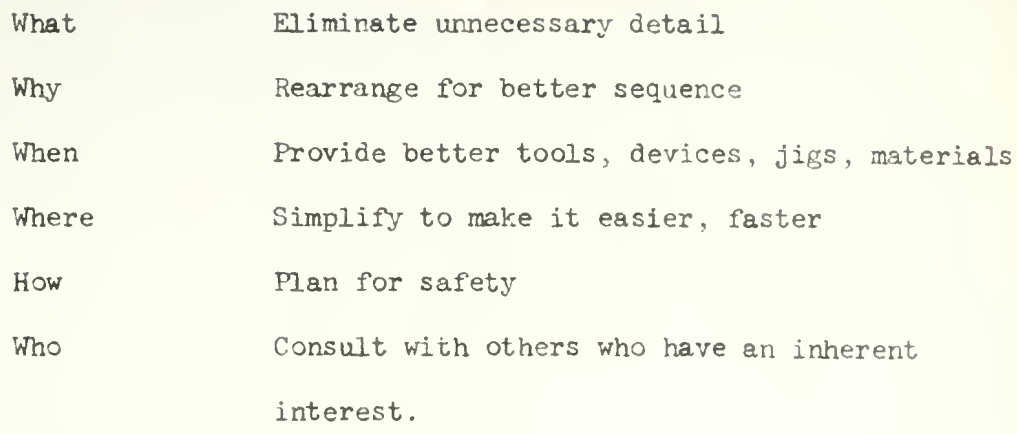

B. Write up a detailed version of the Better Method.

IV Implement the Better Method

A. Sell the method

To the boss

To the foreman

To the workmen

B. Once approval is received, put the better method to work immediately.

c. Continue to use the new method - it may take a little time to learn all the details.

D. Give credit and praise where it is due. 
APPENDIX C

\section{A PARTIAL LIST OF EQUTPMENT SUPPLIERS}

Agfa - Gevaert, Inc.

257 North Street

Teterboro, New Jersey 07608

Bach Auricon, Inc.

6950 Romaine Street

Hollywood, California

Bell \& Howell

Audio Visual Division

7100 McCormick Road

Chicago. Illinois 60645

Eastman Kodak Company

342. State Street

Rochester, New York 14650

I-W Photo. Inc.

15451 Cabrito Road

Van Nuys, California

National Cine Equipment. Inc.

37 West 65 th Street

New York, New York $100 \varepsilon 3$

Paillard Incorporated

1000 Lower Rand

Linden, New Jersey 07036

Photo-Electro Instrumentation

125-10 Queens Boulevard

Kew Gardens New York 11415

Sample Engineering Company

17 North Jefferson Street

Danville, Illinois

Timelapse, Inc.

P. O. Box 4703

Stanford, California 94305 

